\title{
New and Advanced Porous Carbon Materials in Fine Chemical Synthesis. Emerging Precursors of Porous Carbons
}

\author{
Elena Pérez-Mayoral ${ }^{1, *}$, Inês Matos ${ }^{2, *}$, Maria Bernardo ${ }^{2} \mathbb{D}$ and Isabel M. Fonseca ${ }^{2}$ \\ 1 Departamento de Química Inorgánica y Química Técnica, UNED, Paseo Senda del Rey, 9, \\ E-28040 Madrid, Spain \\ 2 LAQV/REQUIMTE, Departamento de Química, Faculdade de Ciências e Tecnologia, Universidade Nova de \\ Lisboa, 2829-516 Caparica, Portugal; maria.b@fct.unl.pt (M.B.); blo@fct.unl.pt (I.M.F.) \\ * Correspondence: eperez@ccia.uned.es (E.P.-M.); ines.matos@fct.unl.pt (I.M.); Tel.: +34-91-398-9047 (E.P.-M.); \\ +351-212-948-300 (I.M.)
}

Received: 15 January 2019; Accepted: 21 January 2019; Published: 1 February 2019

\begin{abstract}
The efficiency of porous carbons in fine chemical synthesis, among other application fields, has been demonstrated since both the porous structure and chemical surface provide the appropriated chemical environment favoring a great variety of relevant chemical transformations. In recent years, metal organic frameworks (MOFs) and covalent organic frameworks (COFs) have emerged as interesting opportunities in the preparation of porous carbons with improved physico-chemical properties. Direct calcination of MOFs or COFs, in the presence or not of others carbon or heteroatom sources, could be considered an easy and practical approach for the synthesis of highly dispersed heteroatom-doped porous carbons but also new porous carbons in which single atoms of metallic species are present, showing a great development of the porosity; both characteristics of supreme importance for catalytic applications. The goal of this review is to provide an overview of the traditional methodologies for the synthesis of new porous carbon structures together with emerging ones that use MOFs or COFs as carbon precursors. As mentioned below, the catalytic application in fine chemical synthesis of these kinds of materials is at present barely explored, but probably will expand in the near future.
\end{abstract}

Keywords: porous carbons; nanocatalysts; metal organic frameworks; covalent organic frameworks; fine chemicals

\section{Porous carbons}

Currently, there is an ongoing effort to achieve sustainable growth, resource use efficiency, minimum waste and overall environmental protection. Increased environmental awareness and the need for competitive and sustainable products and solutions have driven materials research and carbon materials development with it [1-4].

Activated carbon (AC) is an extremely environmental-friendly carbon porous material with increasing number of applications in different domains. These materials present several desirable characteristics such as tunable porosity, light weight, electrical conductivity, chemical and physical stability and a possibility to present different morphologies.

Worldwide, $41 \%$ of its total consumption is attributed to water treatment applications which continue to be the largest application for AC. Air and gas purification corresponds to $30 \%$ of the total, followed by food-processing applications at $14 \%$. Global demand for AC is expected to continue to increase at a rate of $3.5 \%$ per year until 2021. China, the United States of America (USA) and Western Europe are the main contributors to this high growth, driven by new regulations, such as 
control of mercury pollution, and new emerging applications in the energy field (supercapacitors and batteries) $[5,6]$.

Besides these applications mainly related to environmental science, carbon materials have found application in diverse areas such as drug delivery, catalysis, chromatography systems, energy storage, among others [1,7-9].

For many of these applications, controlled porosity and tunable surface chemistry are determinant for AC performance and carbon materials technology have presented extraordinary developments in recent years. The commercial AC available on the market today, as well as many reported in scientific literature, are the result of continuous and intensive research and development (Figure 1) [10].

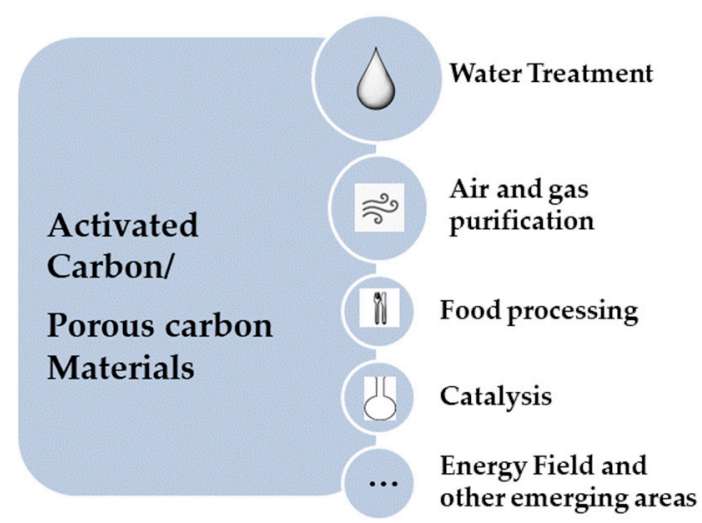

Figure 1. Activated carbon (AC) most current common applications.

AC is a material with highly developed porosity and, consequently, with a high surface area, which can reach more than $2000 \mathrm{~m}^{2} / \mathrm{g}$. The determination of the pore size is fundamental to define the application of an AC. According to the International Union of Pure and Applied Chemistry (IUPAC), pores are classified based on the average pore size: micropores (dimension $<2 \mathrm{~nm}$ ), mesopores $(2 \mathrm{~nm}$ $<$ dimension $<50 \mathrm{~nm}$ ) and macropores (dimension > 50 nm). The base of this classification defines that each group of pores corresponds to a specific function, that is, the macropores are transport pores, the mesopores are transitional pores used both in the adsorption of larger molecules and in the rapid transport of smaller molecules, and micropores are where adsorption occurs (Figure 2) [11].

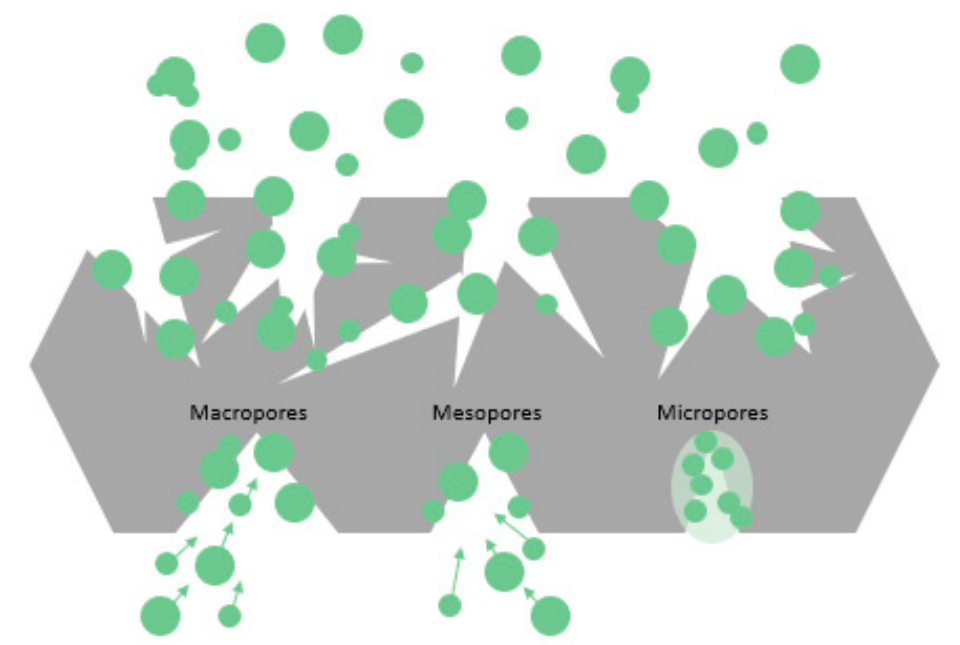

Figure 2. AC pore sizes.

Pores can present a large variety of geometries and may also be classified according to their shape as slit-shaped, cylindrical, spherical, conical, ink-bottle or interstitial. These classifications may be quite relevant for processes that depend on the size and geometry of both the pores and of the interacting 
molecules. The ability to tune the pore size distribution, pore type and format is one of the most attractive features of these materials and it has been the object of many studies, either by selection of the carbon precursor, the synthesis method, or the experimental conditions [12-14].

These solids are mostly composed of carbon, but they have heteroatoms such as oxygen and, to a lesser extent, hydrogen, nitrogen and sulfur, which may already be present in the parent source or are added to the AC during its preparation or at a post-synthesis functionalization step (Figure 3). These atoms are bonded to the surface of $\mathrm{AC}$ in the form of surface complexes or functional groups, which can provide basic or acidic properties to the carbon. The most relevant groups are the ones containing oxygen.

Several physicochemical techniques that include desorption of the oxide layer, neutralization with alkalis, potentiometric, thermometric and radiometric titrations, and spectroscopic methods such as IR spectroscopy and X-ray photoelectron spectroscopy have been used to study the existence of surface groups. Even though these methods have not always yielded comparable results, the more important groups identified are carboxyls, lactones, phenols, quinones, and hydroquinones [10,12,15-17].

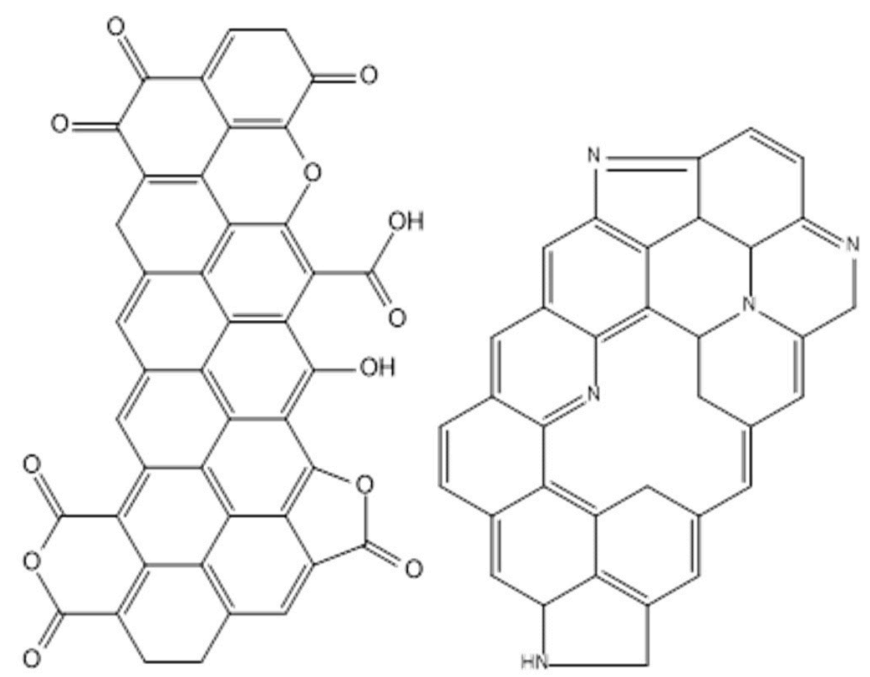

Figure 3. Examples of carbon surface functional groups.

For many applications, the performance of $\mathrm{AC}$ has been proven to be influenced by the surface chemistry. The tune of these properties has been targeted by a variety of processing treatments $[8,9]$. The most common modification is the oxidation process, used mainly to introduce oxygen-containing surface groups $[18,19]$. The dry oxidation method corresponds to the use of oxidizing gases such as steam, carbon dioxide, oxygen, ozone in contact with the AC usually at high temperatures. Wet oxidation refers to the use of oxidizing solutions such as nitric acid, hydrogen peroxide, chlorine water, under mild conditions. As a rule, oxidation increases acidic groups and decreases basicity. The reaction is likely to occur in the most susceptible sites to oxidation, at the defect sites on the carbon surface or at the aliphatic side chains of the carbon, that is, at the peripheral carbon atoms at the carbon/crystallite surface. Because these new functional groups may be formed in the pore opening, some blockage of the pores may occur.

The introduction of other heteroatoms in the carbon framework such as B, N, S and P is also possible, which may allow the tuning of the specific surface area and the electronic properties of the materials, and may also influence their performance in specific fields like catalysis or sensing [2].

The porous carbon materials are also often used as supports for active species, acting either as an inert support material or contributing for the final performance of the materials. This is particularly common for catalysis applications, some environmental applications and more recently in energy-related applications. Two simple techniques are most commonly used for this purpose, impregnation and precipitation-deposition [3]. The biggest drawback of these methods is the difficulty 
controlling metal dispersion on the support; to overcome this issue, other methods have been developed such as micro-emulsion preparation using a surfactant, but with limited success. This could represent one of the main advantage when using metal organic frameworks (MOFs) as precursors of metal-containing porous carbon materials (see Section 2.2).

$\mathrm{AC}$ are one of the most common amorphous carbon materials, primarily made of graphitic sheets with no regular order. Materials research resulted in the development of more types of amorphous carbons with controlled pore sizes and structures. Using hard and soft templating approaches, new ordered porous carbon materials have been developed presenting high surface areas, large pore volumes and tunable textural features. More recently, new highly porous precursors with 2D and 3D ordered structures, such as MOFs and covalent organic frameworks (COFs) have been studied with the main goal of translating these structures to the resulting carbon material. This review intends to focus mainly in the carbon materials obtained from these emerging precursors and its applications in catalysis also offering to the readers a simple overview concerning the most traditional synthetic strategies to prepare porous carbons. Thus, subsequent sections briefly summarize the most classical synthetic approaches and precursors to prepare porous carbons.

\subsection{Conventional Precursors and Classical Synthetic Strategies}

\subsubsection{Activated Carbons-Physical and/or Chemical Activations}

Traditionally, porous carbons have been related to the ACs family obtained from carbonization/activation by using typically lignocellulosic materials and coal as precursors.

Nearly all carbon-containing organic materials can be used as a precursor for AC preparation, and the choice of a suitable precursor strongly depends on its availability and cost. Industrially produced ACs come from wood, mineral carbon (bituminous coal, lignite, anthracite), petroleum residues, peat, coconut shell, nutshells/fruit stones and animal bones [20,21]. Nevertheless, in recent years, the number of publications dealing with the conversion of several types of lignocellulosic wastes to AC has significantly increased [22-24] being the driving force the search for low-cost, sustainable and renewable precursors. Moreover, the use of lignocellulosic wastes from several agro/forest industries represents a potential pathway to solve their waste management problems. In addition, carbonaceous waste such as sludge [25] and tire rubber [26] have been recognized as precursors of porous ACs.

As mentioned above, pyrolysis/activation represents the most classical route to synthesize porous ACs, particularly, physical and chemical activation methods that may consist in a one or two-step processes. Physical activation is a two-step process, which means that the raw material is first carbonized in the absence of oxygen (pyrolysis/carbonization), usually at temperatures between $400{ }^{\circ} \mathrm{C}$ and $850{ }^{\circ} \mathrm{C}$ and with $\mathrm{N}_{2}$ atmosphere, followed by activation of the resulting char with oxidant/gasifying gases such as steam, air, $\mathrm{N}_{2}, \mathrm{O}_{2}, \mathrm{NH}_{3}, \mathrm{CO}_{2}$ or a mixture of these gases, at temperatures around $800-1000{ }^{\circ} \mathrm{C}$, that basically react with the carbon atoms from the carbonaceous matrix $[20,22,24,27]$. The main reactions with the most used gasifying agents, $\mathrm{CO}_{2}$ and water steam, are represented in Equations (1)-(3) respectively.

$$
\begin{array}{rlrl}
\mathrm{C}+\mathrm{CO}_{2} & \rightarrow 2 \mathrm{CO} & \text { (Boudouard reaction) } \\
\mathrm{C}+\mathrm{H}_{2} \mathrm{O} & \rightarrow \mathrm{CO}+\mathrm{H}_{2} & \text { (Water steam gasification) } \\
\mathrm{CO}+\mathrm{H}_{2} \mathrm{O} & \rightarrow \mathrm{CO}_{2}+\mathrm{H}_{2} & &
\end{array}
$$

The development of the porosity during the gasification of the char occurs by the opening of previously inaccessible pores in the char, by the creation of new pores by selective gasification of certain structural components, and the widening of existing pores [20]. The activation with $\mathrm{CO}_{2}$ will produce ACs with narrow micropore size distribution while water steam activation will generate ACs with wider pore size distribution and smaller micropore volume.

The reactions of the gaseous activating agents, as well as the gaseous reaction products, also leads to chemisorbed oxygen which results in the formation of surface oxygen functional groups [20,27]. 
In the case of $\mathrm{NH}_{3}$ treatment, there will be also the introduction of $\mathrm{N}$-containing groups on carbon's surface, although this type of activation/surface modification is usually coupled with other oxidant gas such as $\mathrm{CO}_{2}$ to improve porosity development [27-31].

The importance of the inorganic material contained within the precursors should be mentioned because some of them, particularly salts, oxides and metals of the series of alkali metals, alkali earth metals and transition metals can act as effective catalysts of the gasification reactions.

Regarding chemical activation it can be a one-step or two-step method for the preparation of AC. This involves the impregnation of the precursor (the biomass or the resulting char from the first step of carbonization) with the chemical agent (dehydrating agents and/or oxidants) followed by heating under inert atmosphere at temperatures between $400{ }^{\circ} \mathrm{C}$ and $900{ }^{\circ} \mathrm{C}[20,22,24]$. The most common chemical agents used in chemical activations are $\mathrm{H}_{3} \mathrm{PO}_{4}, \mathrm{H}_{2} \mathrm{SO}_{4}, \mathrm{ZnCl}_{2}, \mathrm{~K}_{2} \mathrm{CO}_{3}, \mathrm{NaOH}$ and $\mathrm{KOH}$. Other chemical agents that can be used, although less common, are $\mathrm{HNO}_{3}, \mathrm{HCl}, \mathrm{H}_{2} \mathrm{O}_{2}, \mathrm{FeCl}_{3}$ and $\mathrm{KMnO}_{4}[20,22-24,27]$.

$\mathrm{H}_{3} \mathrm{PO}_{4}$ and $\mathrm{ZnCl}_{2}$ are examples of chemical agents that are active at relatively low temperatures, around $450-500{ }^{\circ} \mathrm{C}$, being particularly effective for lignocellulosic precursors. $\mathrm{ZnCl}_{2}$ is essentially a catalyst dehydration agent of the lignocellulosic structures, thus acting as template for the creation of microporosity. This means that the volume of micropores developed is similar to the volume of $\mathrm{ZnCl}_{2}$ introduced into the particle, creating an uniform microporosity $[20,22,24]$. For $\mathrm{H}_{3} \mathrm{PO}_{4}$, the mechanisms of porosity development are different since the acid promotes dehydration, depolymerization, condensation and cross-linking reactions in the lignocellulosic precursor, forming phosphate ester linkage structures. The insertion of the phosphate groups creates an expansion that, after removal of the acid, leaves the matrix in an expanded state with an accessible pore structure $[20,22]$. Therefore, $\mathrm{ZnCl}_{2}$ develops both wide micropores and small mesopores and $\mathrm{H}_{3} \mathrm{PO}_{4}$ develops essentially microporosity with some larger mesopores and even macropores [22,24].

The use of alkali metal salts (oxides/hydroxides/carbonates) to prepare ACs requires higher temperatures, usually between $700{ }^{\circ} \mathrm{C}$ and $900{ }^{\circ} \mathrm{C}$. Alkali salts do not act as dehydration agents, which means that they do not react with the precursor but with the char resulting from the carbonization process [20]. The reaction mechanism for the creation of porosity with alkali salts usually involves the following steps: (1) initially, there is a redox reaction where carbon atoms of the formed char are oxidized to $\mathrm{CO}$ or $\mathrm{CO}_{2}$ producing porosity being this gasification catalyzed by the alkali metal; (2) then, the reduction of the alkali metal salt by carbon occurs to produce the metallic atom which will be intercalated between the graphene layers expanding the carbon structure [20,22]. Figure 4 presents an overview of the activation methods to produce AC.

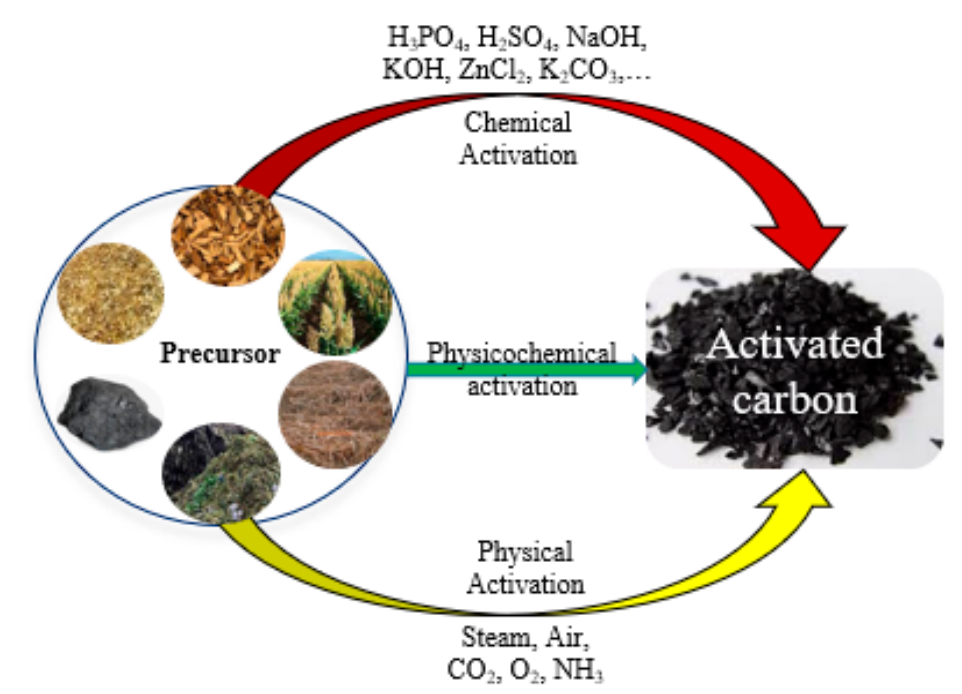

Figure 4. Classical activation methods to produce ACs. 
Chemical activation allows ACs to be produced with high surface areas, but the washing of the resulting materials to remove the residuals of activating agents makes the process time and energy consuming, expensive and environmentally non-friendly. On the other hand, physically ACs are obtained at higher temperatures of activation and there is a poorer control of the porosity. It should be noted that physical and chemical activation can also be used simultaneously.

\subsubsection{Hydrothermal Carbonization}

Hydrothermal carbonization (HTC) is another route widely applied to produce porous carbons. It has been successfully used to convert biomass precursors such as carbohydrates (glucose, xylose, maltose, sucrose, amylopectin, starch, cellulose) but also lignocellulosic precursors [32-36]. As per classical pyrolysis, the final product will be a char (named as hydrochar), but in HTC the precursor is thermochemically converted in the presence of subcritical water, which represents an advantage to produce porous carbons from "wet" precursors. HTC occurs at mild temperatures around $180-260{ }^{\circ} \mathrm{C}$ and under self-generated pressures around 2-6 MPa (steam pressure) [32,37]. The resulting hydrochar may present an incipient porosity and has to be post-synthesis activated through physical and/or chemical methods to generate porosity. A major difference between pyrochar (from dry pyrolysis) and hydrochar is the amount of oxygenated functional groups which will be significantly higher on the latter one, therefore HTC is also quite frequently used to enrich the resulting carbon materials surface with functional groups.

High temperature HTC, although not so common, is also used to produce porous carbons such as carbon nanotubes, graphitic carbon materials and ACs [38-41]. In this case, the process occurs with supercritical water at temperatures higher than $374{ }^{\circ} \mathrm{C}$ and at pressures higher than $25 \mathrm{MPa}$ [42,43].

Different chemical agents that will act as catalysts, activation agents or templates have been used in-situ HTC to increase and tune the porous properties of the synthesized HTC carbon material. Some authors have used $\mathrm{ZnCl}_{2}, \mathrm{H}_{3} \mathrm{PO}_{4}$ or even eutectic salt mixtures as catalyst/activating agent during HTC of different biomass precursors (coconut shells, almond shells, hemp residues, sawdust, glucose) [44-46] with significant improvements in the surface area of the final carbon materials.

\subsubsection{Microwave-Assisted Carbonization/Activation}

Microwave (MW) heating to assist carbonization and/or activation processes has been quite used to obtain porous carbons since it offers the advantages of accelerating the rate of chemical reactions at lower temperatures providing uniform heating [47,48]. By comparison with conventional heating, porous carbons obtained from MW processes might present much higher surface areas. Nevertheless, if quite difficult to compare between the two heating processes mainly due to unknown temperature of the sample in MW heating and due to the different heat transfer mechanisms. With a microwave method both carbonization and physical or chemical activation steps can be conducted simultaneously; there is also the possibility of a two-step process which means that there is a first step where the char is produced (by conventional heating or by microwave heating) followed by the activation step under microwave irradiation. Usually, the microwave power for physical activation is in the range of $750-3000 \mathrm{~W}$, while for chemical activation this range is 200-900 W [23].

\subsubsection{Porous Carbon Gels}

Traditional porous carbon gels are prepared through the sol-gel synthesis that consists of the polycondensation/polymerization reaction in aqueous solutions of hydroxybenzenes such as resorcinol, phenol, phloroglucinol, and cresol, with aldehydes such as formaldehyde and furfural, catalyzed by chemical agents like $\mathrm{Na}_{2} \mathrm{CO}_{3}, \mathrm{NaOH}, \mathrm{HCl}$, acetic acid, among others $[14,49,50]$. The reagents are initially mixed to form a stable suspension of colloidal solid particles, and then this sol phase will suffer gelation (polymerization) which basically consists in the creation of a three-dimensional porous network formed by polymeric chains (gel). The gelation step occurs at temperatures below $100{ }^{\circ} \mathrm{C}$. The ageing of the formed gel is critical to promote the crosslinking 
degree of the formed polymer clusters and it will strongly affect the porosity of the final carbon gel. The ageing step may take $3-7$ days at temperatures around $80-90^{\circ} \mathrm{C}$. The final wet gel must be dried in order to remove the impregnated solvent but keeping in mind that the gel structure must be strictly preserved in order to avoid a collapse of the structure because it is in this step that the formed porosity will became accessible. Depending on the drying method, different organic gels with different nomenclature are obtained: supercritical drying, freeze-drying and ambient drying originates aerogels, cryogels and xerogels, respectively [14]. Obviously, the simplest method is the ambient temperature drying that simply consists in the exchange of the water used as solvent by an organic solvent with lower surface tension (to avoid the collapse of the structure) such as acetone, followed by the solvent evaporation at room temperature and at atmospheric pressure. In supercritical drying, the first exchanged solvent (acetone) is further exchanged by carbon dioxide $\left(\mathrm{CO}_{2}\right)$ which is then removed at high pressure. In the freeze-drying process, the solvent is frozen and the gel is dried by sublimation at low pressure $[14,49,50]$.

Finally, to produce the carbon gel, the dried gel is carbonized under inert atmosphere at high temperatures, usually between $600{ }^{\circ} \mathrm{C}$ and $900{ }^{\circ} \mathrm{C}$, with very low heating rates, to widen the narrow pores formed during the previous steps. Although the carbonization step has importance for the final porous structure of the carbon gel, the gelation and curing stages are the most critical stages to tune the carbon gel porosity.

The use of biomass precursors, especially polysaccharide, to obtain carbon xerogels and carbon aerogels have been reviewed $[14,51]$ and focused on the Starbons ${ }^{\circledR}$ materials. The synthesis steps are quite the same but, in the gelation step an expanded gel structure is obtained followed by a slow recrystallization of the polymeric chains. Another different feature is the necessity of an acid catalyst during the carbonization of the gel, otherwise the melting of the polymer will occur before dehydration.

Carbon gels from HTC of carbohydrates have been also quite studied [14,51]. Basically, with HTC conditions, these precursors undergo condensation, polymerization, and aromatization reactions to generate porous carbon materials. However, crosslinking promoter agents such as phloroglucinol must be used as well as other additives [14,51,52].

\subsubsection{Templating Strategies}

The control of the pore structure of carbon materials in order to create uniform and ordered porosity can be undertaken by different templating strategies which are usually classified as hard-template and soft template methods.

Hard template methods (sometimes called nanocasting) include the use of an inorganic solid as template mold. Zeolites, several silicas, clays, among others, are traditionally used as template materials $[14,53,54]$. In these methods, the template is impregnated with the carbon precursor (sucrose, furfuryl alcohol, phenolic resins, acrylonitrile, etc.) followed by carbonization of the generated composite. Most of the times the carbon precursor used will undergo polymerization similar to organic gels inside the porous network of the template. Finally, the leaching of the template from the resulting carbon material will liberate the pores formed. The major drawback of this synthesis method is the latter step, since the leaching of the templates might include the use of the undesirable hydrofluoric acid.

In conventional soft template methods, the carbon precursor polymerizes in the presence of a surfactant agent that is used as template. The most common surfactant agents used are amphiphilic triblock copolymers consisting of polyethylene-polypropylene oxides such as Pluronics ${ }^{\circledR}$. The template is then eliminated through the carbonization treatment. The surfactant forms micelles during the process that act as templates for the construction of pores [14,54-56]. Compared with the hard template method, the number of steps in soft templating syntheses are significantly reduced which is an advantage. However, the desired and predictable final porous structure is not so straightforward as with hard templating. 


\section{Covalent Organic Frameworks (COFs) and Metal-Organic-Frameworks (MOFs) in the Synthesis of Porous Carbons. Advanced Synthetic Strategies and Applications}

In recent decades, studies concerning COFs and MOFs have exponentially increased because of its wide variety of application fields.

MOFs are an exciting type of porous materials known as crystalline porous coordination polymers, consisting of poly-dentated organic ligands coordinating metallic centers [57,58]. Interestingly, a great number of metals can be applied on the MOF synthesis [59], the coordination of different metal ions with distinct organic components allowing a great molecular diversity. Generally, these materials show low densities, large surface areas and high pore volumes integrating permanent porosity, in which metals are uniformly distributed. While the development of the porosity in most of the inorganic solids requires the use of structural directing agents, when synthetizing MOFs the engineering of the metal centers and also of organic ligands have a direct impact on the size and shape of the porosity [60]. Nevertheless, MOFs can also incorporate different active functions by carefully selecting the organic and metal components. All these variables imply that the composition, functionalities and texture of this type of materials can be tuned as function of a specific use, covering gases sorption and separation [61], energy storage and conversion [62], chemical sensing [63], catalysis [64], degradation of organic pollutants [65] and even drug delivery [66], among others.

On the other side, COFs are highly porous materials that present controllable pore geometries with exceedingly high pore volumes. Differently from MOFs, these materials do not possess a metal center and they are formed by covalent bonding of organic building blocks. This allows for a well-defined crystalline porous structure with the ability to tailor functionalities, giving COFs the potential to be used in many applications $[67,68]$. These materials have been primarily studied in the context of gas capture and separation [69], heterogeneous catalysis [70-72] and energy storage [68].

However, the modest stability of both MOFs and COFs materials strongly limits their applications. The preparation of advantageous multifunctional nanomaterials from COFs and MOFs including porous carbons, nanostructured metal oxides and carbon-metal/metal oxide hybrids is a current growing topic [73]. The goal of this paper is, then, to highlight some of the synthetic strategies employed to produce porous carbon materials from emerging precursors such as COFs and MOFs as well as its implication in catalytic reactions for fine chemical synthesis.

\subsection{Porous Carbon from COFs}

COF materials are promising precursors for the preparation of highly tailored porous carbons [68]. There are two main components in the preparation of COFs: the linkages and the linkers, and various organic molecules have been used as these building blocks. This allows for tailored heteroatom species, high surface areas, and controllable structures at the molecular level. For that reason, more than 100 structures have been reported $[74,75]$.

Because its covalent frameworks are more tolerant to harsh treatments, a closer structural relation between the COFs precursors and the porous carbon obtained is expected. All these characteristics make COFs outstanding templates or precursors to fabricate porous carbons [76]. The simplest procedure is the direct carbonization of the porous organic precursor under controlled conditions. The resulting carbon is normally a microporous material, owing its porosity not only to the porous structure of the precursor but also to the carbon burn off due to the carbonization process. Different morphologies can be obtained just by careful selection of the precursors [75].

Feng et al. [77] synthesized one-dimensional carbon fibers and tubes through a simple carbonization of as-formed carbon-rich tubular and fiber-like polyphenylene precursors under argon. Microporous carbon nanotubes (CNTs) and carbon nanofibers (CNFs) with a surface area up to $900 \mathrm{~m}^{2} / \mathrm{g}$ were obtained and tested in advanced electrodes in an electrochemical double-layered capacitor.

Using 2D covalent organic polymer precursors Xiang et al. [78] obtained a $\mathrm{N}$-doped graphitic porous carbon, opening the possibility of controlling the exact location of the heteroatom. 
These materials showed good correlation between electrocatalytic activity and the $N$-doped carbon characteristics.

A microporous sulfur doped carbon was prepared by Paraknowitsch et al. [79] by using a thienyl-based polymer as a precursor. Bhosale et al. [80] prepared nitrogen and sulphur conjugated porous polymers using Sonogashira coupling reaction to be used as precursors of doped carbon porous materials. The carbons obtained were then successfully used for oxygen reduction and energy storage.

An imine-linked polymer prepared by Schiff base condensation under catalyst-free conditions resulted in microporous polymer materials with $744 \mathrm{~m}^{2} / \mathrm{g}$ surface area [81]. The direct pyrolysis of the polymer allows the formation of $\mathrm{N}$-doped carbons with narrow micropore size distributions, and a high density of nitrogen functional groups (5.58-8.74\%). These porous carbons were used for $\mathrm{CO}_{2}$ capture and the carbon obtained by pyrolysis at $800{ }^{\circ} \mathrm{C}$ revealed a calculated adsorption capacity of $7.41 \mu \mathrm{mol}$ of $\mathrm{CO}_{2} / \mathrm{m}^{2}$ at 1 bar and $25^{\circ} \mathrm{C}$, the highest ever reported for porous carbon adsorbents. The authors also demonstrated the stability and easy regeneration and reuse of the materials without meaningful loss of $\mathrm{CO}_{2}$ adsorption capacity.

In the search for new materials for a high-performance lithium sulfur battery, the direct carbonization of an imine-linked COF, Triformylphloroglucinol and P-phenylenediamine COF (TpPa-COF) allowed the preparation of graphitic $N$-doped carbon to be used as a sulfur host material in the preparation of a cathode material in the lithium sulfur battery [82].

Through the direct carbonization of structured porous organic frameworks at high temperature, it was possible to prepare hollow, spherical nitrogen-rich porous carbon shells [83]. The material was composed of amorphous carbon with micropores on the shell frame and with specific surface areas as high as $525 \mathrm{~m}^{2} / \mathrm{g}$.

Kim et al. [84] successfully synthesized microporous $N$-doped carbons by the direct carbonization of an azine-linked two-dimensional molecular network. The carbonized COF presented high specific surface area $\left(1596 \mathrm{~m}^{2} / \mathrm{g}\right.$ ), uniform micropores (less than $1 \mathrm{~nm}$ ), and $\mathrm{N}$-doped graphitic carbon structure. Furthermore, the study of the micropore-forming process revealed that the formation of nitrogen gas during the thermal degradation of the azine bond contributes to the microporous structure formation. These materials showed an enhancement of the electrochemical capacitance.

Zhu et al. [85] prepared free standing carbonaceous membrane of polymer structures. In one approach, the author performed the pyrolysis of a pyrrole-ring-containing polymeric membrane based on the superacid-catalyzed copolymerization of acetyl monomers. In another approach the porous, nitrogen-doped carbonaceous free-standing membrane was obtained by carbonization of a triazole-functionalized-triazine framework [86]. The resulting carbonaceous membranes presented an exceptional ideal $\mathrm{CO}_{2} / \mathrm{N}_{2}$ selectivity and $\mathrm{CO}_{2}$ permeability.

Figure 5 presents some examples of the building blocks used in the preparation of COFs precursors in an effort to obtain new carbon porous structures.

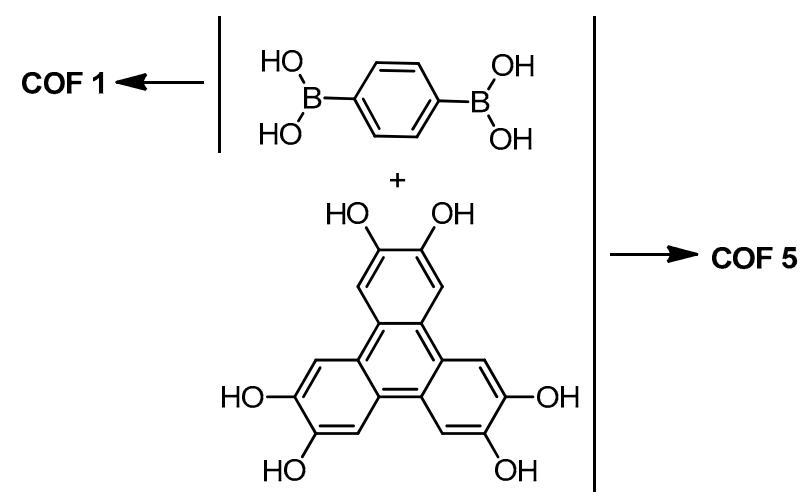<smiles>Nc1ccc(N)cc1</smiles>

Figure 5. Typical building blocks used in the preparation of COFs as precursors for porous carbons. 
In all the aforementioned examples, the control of pyrolysis temperature and heating rate is an important experimental factor. The thermal treatments are generally performed between $600{ }^{\circ} \mathrm{C}$ and $1000^{\circ} \mathrm{C}$, using low heating rates (from $2{ }^{\circ} \mathrm{C} / \mathrm{min}$ up to a maximum of $15^{\circ} \mathrm{C} / \mathrm{min}$ ); higher temperatures normally yielding higher porosity. In any case, the surface areas obtained by direct carbonization are not very high.

These procedures have proven the possibility of tailored carbons with specific morphologies and the easy/efficient heteroatoms incorporation on the porous carbon structure. Taking advantage of the simple preparation process, a wide availability of precursors, flexible control of the structure, and an easier adjustment of the amount of heteroatoms, it seems that by a careful selection of precursor frameworks and carbonization conditions many new and improved materials are yet to be developed. However, some authors recognize that the rational design of COF precursors remains a challenge due to the intangible structural association between the sacrificial COFs and the final material [87].

Chemical and physical activation are well known procedures in the preparation of porous carbons with highly developed porosity, as discussed previously. In an attempted to improve the textural properties of the carbon materials obtained by pyrolysis of $\mathrm{COF}$, some authors have used this promising strategy. Lee et al. [88] using covalent triazine frameworks (CTFs), a subclass of porous organic polymers (POPs) first reported by Thomas [89], observed that the chemical and textural properties of starting porous organic polymers have profound effect on the resulting porosity of the $\mathrm{KOH}$ chemically activated obtained porous carbon material. The chemical activation of microporous CTF- 1 using KOH at $700{ }^{\circ} \mathrm{C}$ predominantly showed pore deepening, leading to an increased surface area of $2367 \mathrm{~m}^{2} / \mathrm{g}$ and significantly enhanced gas adsorption properties with $\mathrm{CO}_{2}$ uptake capacities up to $6.0 \mathrm{mmol} / \mathrm{g}$ at 1 bar and $1.45 \mathrm{mmol} / \mathrm{g}$ at $0.15 \mathrm{bar}$ and $273 \mathrm{~K}$. The authors also observed that for some materials the activation resulted in a decrease in its surface area and also in the conversion of mesopores into the micropores. In fact, intense chemical or physical activation may induce the collapse of the structures. The results also suggest the critical role of chemical and pore characteristics of porous organic polymers in the outcome of chemical activation [88].

In another work [90] using a low-cost porous covalent triazine polymer obtained by the Friedel-Crafts reaction, the authors prepared two sets of porous AC, one by direct carbonization and the other with $\mathrm{KOH}$ as activating agent. The material obtained via chemical activation possessed a high surface area of $2271 \mathrm{~m}^{2} / \mathrm{g}$ and large micro/total pore volumes of $0.87 / 0.95 \mathrm{~cm}^{3} / \mathrm{g}$, with narrower micropore size distributions than the porous carbon prepared without activation.

Using a triazine-based hyper crosslinked polymer, an organic-inorganic hybrid framework and spherical morphology was fabricated by a typical Friedel-Crafts reaction. It was possible to retain the spherical morphology of the polymers after $\mathrm{KOH}$-activation carbonization, while enhancing the porosity. The surface area and micropore volume were easily controlled ranging from 237 to $2058 \mathrm{~m}^{2} / \mathrm{g}$, and $0.10-0.93 \mathrm{~cm}^{3} / \mathrm{g}$, respectively, as the carbonization temperature rises from 500 to $600{ }^{\circ} \mathrm{C}$ and then to $700{ }^{\circ} \mathrm{C}$ [82].

In order to produce a microporous carbon supercapacitor electrode, carbonization followed by $\mathrm{CO}_{2}$ activation was used in the preparation of highly microporous carbon materials from a triazine covalent organic framework. Upon $\mathrm{CO}_{2}$ activation more micropores were formed, accompanied by an increase in the surface area without sacrificing the narrow pore size distribution. The carbon activated at $900{ }^{\circ} \mathrm{C}$ presented a specific capacitance significantly higher than that of a commercial AC ranking among the highest reported to date [91].

Many of the aforementioned works are related to covalent triazine-based frameworks, the reason being their great potential for practical applications, for example, gas storage, separation, catalysis, and electronic devices, their high chemical and thermal stability, and their relatively easy and cheap synthesis. All these make CTFs stand out as promising materials for testing in a wide range of applications [92,93].

Besides $\mathrm{N}$ and $\mathrm{S}$ doped carbon, B-doped porous carbons have attracted attention in energy applications, including gas and energy storage. Hierarchically porous $B$-doped COF-derived carbons 
were prepared using the molten-salt method. The resulting carbon porous material presented enhanced surface area and $\mathrm{H}_{2}$ storage capacity, as well as enhanced rate performances as supercapacitor electrodes. The author used COF- 5 as a precursor and template, and the molten-salt $\mathrm{ZnCl}_{2}$ as a solvent and porogen to fabricate hierarchically porous B-doped carbons [94].

Aiming at the incorporation of $\mathrm{Fe}$ in the final $\mathrm{N}$ and $\mathrm{S}$ doped carbon material, a new mixed solvent of molten $\mathrm{FeCl}_{3}$ and $\mathrm{S}$ was used for CTF polymerization. This proved to favor the formation of $\mathrm{Fe}-\mathrm{N}_{\mathrm{x}}$ site and $\mathrm{S}$ doping in the subsequent pyrolysis process more convenient [87].

Another approach is the use of microwave irradiation. Bai et al. [95] developed a synthetic method for the production of functionalized ultra-microporous carbons by "segregated" microwave irradiation using COFs as $\mathrm{C}$ and $\mathrm{N}$ source. The carbonaceous COFs could retain the bulk morphology of the precursors and possess a unique functional group (cyano) useful in further modifications. This material was successfully used in uranium adsorption studies from a simulated nuclear effluent. The study and characterization of the carbonaceous materials also revealed their acid/base stabilities checked using $\mathrm{HNO}_{3}$ and $\mathrm{NaOH}$, and their radiation stability when irradiated at ambient temperature by $60 \mathrm{Co}$ gamma source (dose ratio: $6.2 \mathrm{kGy} / \mathrm{h}$ ) in the dose-range of 10-100 kGy.

A major driving force for the development of new metal-free carbon materials is the design of electrochemical catalysts for fuel cells [96]. Electrical conductivity for electron transport, optimal porosity for ion motion and catalytic sites are the necessary requirements for this application. $\mathrm{Xu}$ et al. [97] presented a new methodology to achieve this carbon catalyst: the use of a 2D COF in combination with a suitable template to guide the pyrolysis. The authors employed phytic acid (PA) as a template and treated a 2D COF (4,4', $4^{\prime \prime}-(1,3,5$-triazine-2,4,6-triyl)trianiline (TAPT)-2,5-dihydroxyterephthalaldehyde (DHTA)-COF). The function of PA was to exfoliate the heavily stacked layers of 2D COFs into a few layers that help to form small-sized carbon sheets, and to guide the conversion of 2D COF layers into 2D carbons during pyrolysis while triggering the porous structure of the resulting 2D carbons. The use of PA also allowed doping the carbon sheets with phosphorus. The catalysts attain higher performance then $\mathrm{Pt} / \mathrm{C}$ with long-time stability, and methanol tolerance.

Hybrid materials resulting from the mixing of COF-derived microporous carbon with polymers [98], or prepared via growing the porous COF on conductive multi-walled carbon nanotubes (MWCNTs) [99], or by using COFs doped with metal cations, as precursors for the in situ encapsulation of metal particles into $\mathrm{N}$ doped hollow carbon spheres (NHCS) through a controlled carbonization process [100], are some of the recent reported carbon-based materials developed using COFs.

\subsection{Porous Carbons from MOFs}

Due to the inherent characteristics and the great variety of MOFs, these materials are excellent precursors for the synthesis of highly porous carbons by carefully pyrolysis [101], also including metal-based porous materials such as metal oxides, carbides, nitrides, sulfides and phosphides [102].

More specifically, metal carbon hybrids and even metal-free porous carbons can be produced from MOFs under strictly controlled thermal conditions. Generally, if the carbonization takes place under inert gas flow, the metal/carbon hybrids or metal-free porous carbon materials will be obtained whereas the aerobic thermal treatments often lead to nanostructured metal oxides. In this sense, both highly porous materials are found to be promising materials with multiple applications, particularly in catalysis. Interestingly, ordered porous carbons with a high surface area and density of catalytic active sites, highly dispersed heteroatoms and controllable porosity, showing better catalytic performances, can be easily prepared from MOFs avoiding the use of templates. In general, porous carbons from MOFs can show the morphology and hierarchical porosity inherited from the MOF patterns making possible a rational design of the porous structures with improved catalytic performance, paying attention to energy storage and synthesis of valuable compounds. This review summarizes some relevant aspects in the synthesis and applications of porous carbons using MOFs, as carbon precursors but also as sacrificial templates using an additional carbon sources, an area in rapid expansion. 


\subsubsection{MOFs as Precursors for Metal-Free Porous Carbon Synthesis}

Development of highly porous carbon materials from MOFs including their potential applications has been recently revised [73]. MOF-5 and ZIF-8 and related series constitute the most investigated metal-organic networks to produce porous carbon materials. In this section, and in order to summarize the potential applicability of these highly interesting porous carbons, some representative examples have been chosen and commented upon. In this sense, a great variety of metal-free porous carbons obtained by direct pyrolysis of MOFs presenting interesting textural properties useful as super-capacitators have been developed. Zhang et al. [103] reported the synthesis of metal-free mesoporous carbon materials with high surface area (up to $1800 \mathrm{~m}^{2} / \mathrm{g}$ ) by thermal decomposition of MOF-5. The reaction occurs at approximately $400{ }^{\circ} \mathrm{C}$, comprising the release of $\mathrm{CO}_{2}$ and benzene producing $\mathrm{ZnO}$ covered by amorphous carbons. In this case, acid treatment with $\mathrm{HCl}$ allowed the $\mathrm{ZnO}$ removal. At the same time, Hu et al. [104] described the preparation of three types of porous carbons by direct thermolysis of MOF-5, at $900{ }^{\circ} \mathrm{C}$, reporting interesting mechanism insights. It is noteworthy that $\mathrm{Zn}$ cations were reduced and vaporized, avoiding additional washing treatment. The authors also synthesized other carbons impregnating MOF-5 inside and outside the pore structure with phenolic resin and carbon tetrachloride and ethylenediamine, as different carbon sources, in which the carbon source influence the pore structure. In order to control the microstructures, after carbonization all the samples were activated using $\mathrm{KOH}$ modifying the textural properties and pore structure. It is well known that carbons with developed mesoporosity in electric double-layer capacitors allows a faster mass transfer, with mesoporous carbons exhibiting the best capacitance whereas the microporosity has a major impact enhancing the surface area.

Environmentally friendly and non-toxic carbon sources such as glucose [105] or glycerol [106,107] have been also employed in the synthesis of hierarchically micro- and mesoporous carbons by carbonization of MOF-5 useful in the fabrication of electrodes. Liu et al. [101] reported the synthesis of nanoporous carbons with large pore volume and high $\mathrm{S}_{\mathrm{BET}}$ using MOF-5 but also incorporating furfural alcohol, as an additional carbon source, by using the incipient wetness method. Samples were pyrolyzed at different temperatures (from $530{ }^{\circ} \mathrm{C}$ to $1000{ }^{\circ} \mathrm{C}$ ) observing a dependence of the $\mathrm{S}_{\mathrm{BET}}$ with the temperature (ranging from $1141 \mathrm{~m}^{2} / \mathrm{g}$ to $3040 \mathrm{~m}^{2} / \mathrm{g}$ ). The presence of $\mathrm{Zn}$ species on carbons strongly depends on the carbonization temperature. A totally metal-free sample was obtained at $1000{ }^{\circ} \mathrm{C}$ whereas the presence of $\mathrm{Zn}$ was observed at decreased temperatures $\left(800^{\circ} \mathrm{C}\right)$. These materials exhibited excellent electrochemical performance as an electrode material for electrical double-layer capacitors even more than carbons prepared from SBA- 15 mesoporous silica. Particularly, the use of glycerol together with the addition of different amounts of $\mathrm{Bi}\left(\mathrm{NO}_{3}\right)_{3} \cdot 5 \mathrm{H}_{2} \mathrm{O}$ has an important impact on the surface area and pore size distribution of the materials.

Hierarchically porous carbons prepared from direct carbonization of different MOF have been also found to be exceptional candidates for the $\mathrm{CO}_{2}$ capture [108] and hydrogen storage [109]. Srinivas et al. [108] prepared different porous carbons from three different MOFs-MOF-5, MOF-74 and MIL-53-presenting high surface areas (up to $2734 \mathrm{~m}^{2} / \mathrm{g}$ ) and enhanced total pore volumes (up to $5.53 \mathrm{~cm}^{3} / \mathrm{g}$ ). Changes in the synthesis conditions of MOF precursors strongly influenced the texture and porosity of these materials. In fact, the enhancement of both surface area and pore volume in these samples could be due to the presence of millimetre-sized crystals in MOF obtained in high yields. During the carbonization process, $\mathrm{ZnO}$ and carbon with barely developed porosity are produced in a temperature range of $600{ }^{\circ} \mathrm{C}$ to $800{ }^{\circ} \mathrm{C}$. At higher temperature (up to $900{ }^{\circ} \mathrm{C}$ ) $\mathrm{ZnO}$ is reduced and the evaporation of $\mathrm{Zn}$ species and $\mathrm{CO}$ release take place yielding hierarchical highly porous carbons.

Very recently, Wang et al. [109] designed a sophisticated synthetic strategy to prepare MOFs with flake-like morphology by using layered metal hydroxides as templates and a self-sacrificed metal source. Organic ligands (2-methylimidazole) capture the metal cations from the metal hydroxide, previously prepared dispersing $\mathrm{Zn}^{2+}$ and $\mathrm{Co}^{2+}$ in the same molar ratio, yielding a bimetallic MOF, ZnCo-ZIF-1, in which the Zn and Co coexist and are uniformly distributed. Macroporous carbon from this MOF retaining the flake morphology is reported as a promising candidate as supercapacitor. 
Porous carbon with controlled textural properties from MOFs are also interesting materials with capacitive deionization. In this sense, Wang et al. [110] reported the synthesis of various porous carbons from $\mathrm{Zn}$-containing MOFs at $1000{ }^{\circ} \mathrm{C}$ - ZIF-8, [ $\left.\mathrm{Zn}(\mathrm{MeIM})_{2}\right],\left[\mathrm{Zn}_{4} \mathrm{O}(\mathrm{bdc})_{3}\right]$, and $\mathrm{Zn}_{3}$ (fumarate $)_{3}$-with well-maintained shapes after pyrolysis of precursors exhibiting high performances. Interestingly, Ding et al. [111] reported on the use of crystalline bimetallic metal-organic frameworks based on ZIF-8 and ZIF-67, containing both Zn and Co metallic species, as precursors of porous carbons useful in the development of membranes for water desalinization. Co species in these cases can act as catalytic species inducing the formation of graphene-like carbons. Although most of the metal species were removed by acidic treatment using $\mathrm{HCl}$ solutions, some $\mathrm{Zn}$ and Co nanoparticles remain inserted on the graphitic layers. It is noteworthy that the surface area and graphitization of carbon can be moldable as function of the molar metal ratio used in the synthesis of MOF precursor.

\subsubsection{MOFs as Precursors for Carbon Hybrids}

Carbon-based materials such as nanotubes, graphene and mesoporous carbons, particularly doped porous carbons with controlled morphology and hierarchical porosity are considered advanced materials as interesting alternative to the traditional graphite anodes in lithium batteries with high catalytic performances [112,113]. Very recently, MOF-derived porous carbons with improved textural properties have been also applied in electrochemical energy storage devices $[114,115]$. It is highlighted below some relevant and interesting examples comprising metal oxides, $\mathrm{N}$ - and $\mathrm{S}$-doped carbon hybrids.

$\mathrm{ZnO}$ nanosheets have aroused great attention because of their unique physico-chemical properties which make them useful materials in energy storage, sensing and catalysis, among others. Recently, Li et al. [114] reported an easy methodology to prepare $N$-doped MOF-derived porous carbon by in situ carbonization of $\mathrm{Zn}$-based MOF, in which $\mathrm{ZnO}$ nanosheets were growing. Zn-BDC-TED, a MOF formed from terephthalic acid (BDC) and triethylenediamine (TED) as ligands was used. In this case, the inherent molecular structure of $\mathrm{Zn}$-BDC-TED induces the growth of $\mathrm{ZnO}$ nanosheets during the thermal process.

It has been theoretically and experimentally demonstrated that the lithium-ion storage capacity also depends on the large nitrogen-doping degree for $N$-doped graphene. However, the maximum nitrogen loadings reported for $\mathrm{N}$-doped carbons do not exceed $10 \%$. In this sense, $\mathrm{N}$-doped amorphous carbons derived on ZIF-8 with very high nitrogen content (up to 17\%) showing ultra-high lithium storage have been reported [114]. These materials were synthetized by thermal treatments also varying the pyrolytic pressure showing significant differences. All samples presented pores and interconnected globular cavities, and the sample pyrolyzed under vacuum with cavities smaller and denser. $\mathrm{N}$-doped porous carbon materials have been also prepared from direct pyrolysis of pyridine-containing MOF ([Zn(bpdc)DMA] by varying the carbonization temperature $\left(800^{\circ} \mathrm{C}\right.$ and $\left.1000{ }^{\circ} \mathrm{C}\right)$ [116]. Textural properties and composition of the materials depend on the carbonization temperature. The carbon prepared at lower temperature exhibit higher surface area and pore volume and higher nitrogen loadings, whereas the highest carbonization temperature induced a better graphitization degree and conductivity.

$\mathrm{Xu}$ et al. [117] developed an electrochemical sensor based on doped nitrogen-ordered porous carbon highly graphitized for detection of biomolecules such as uric acid, catechol and hydroquinone showing good electrical conductivity and electrochemical activity. In another way, Pan et al. [118] reported an interesting synthetic approach to prepare $\mathrm{N}$-doped hierarchical porous carbons with high nitrogen loading (up to $10 \%$ ) and enhancing microporosity, showing good $\mathrm{CO}_{2}$ adsorption properties and high selectivity for $\mathrm{CO}_{2} / \mathrm{N}_{2}$. The developed methodology is characterized by the introduction of $\mathrm{K}^{+}$ions into the pores of the MOF precursor, prepared by coordinating zinc acetate dihydrate with adenine and $4,4^{\prime}$-biphenyl dicarboxylic acid $\left(\mathrm{H}_{2} \mathrm{BPDC}\right)$. The $\mathrm{K}^{+}$ions were introduced by cation exchange, acting as an in situ activation agent during the carbonization process, thus avoiding the use of $\mathrm{KOH}$ as post-treatment. 
Magnetic nitrogen-doped porous carbon has been also reported by pyrolysis of bimetallic MOF, based on the coordination of $\mathrm{Zn}^{2+}$ and $\mathrm{Co}^{2+}$ ions with 2-methylimidazole, and useful in the removal of Norfloxacin (an antibiotic frequently used for the infectious diseases treatment) [119]. The porosity development take place during the Zn evaporation whereas highly dispersed Co species confer magnetic properties to the porous carbon. Co nanoparticles acting as catalyst produced the graphitization of the carbon structure responsible for the enhanced adsorption properties.

Highly porous $\mathrm{N}$-doped carbons prepared from a $\mathrm{Zn}$-MOF presenting high surface area has been also used as support for the synthesis of bimetallic composites active in the electrocatalytic hydrogen and oxygen evolution reactions [120].

$\mathrm{Li}-\mathrm{S}$ batteries are the most promising candidates as successors to Li-ion ones. As mentioned above, the morphological and texture characteristics of the porous carbons are highly important issues to be considered. The confinement of sulfur inside the porosity of MOFs is possible, however, the electrochemical properties of those are inferior to the carbon cathodes. In this regard, Dhawa et al. [121] prepared a magnesium 1,4-benzenedicarboxylate $\mathrm{MOF}$ as the precursor of a hybrid $\mathrm{Mg} / \mathrm{MgO}$ porous carbon able to immobilize sulfur. While the presence of the carbon matrix increases the conductivity, $\mathrm{MgO}$ deserves support for sulfur immobilization, avoiding the use of $\mathrm{S}$ dissolution into the electrolyte.

\section{Porous Carbons from MOFs in Fine Chemical Synthesis}

The catalytic properties of porous carbons from emerging precursors such as MOFs are an interesting research field still to be explored. However, some efforts focused onto the application of this type of porous carbons in catalytic processes for the synthesis of fine chemicals including oxidation, hydrogenation reactions and some condensation reactions have been reported. Subsequent sections summarize some catalytic applications of porous carbons from MOFs for the synthesis of valuable compounds.

- Hydrocarbon oxidation

Selective hydrocarbon oxidation is one of the major challenges in organic synthesis because of the corresponding oxygen derivatives are considered important valuable compounds. Specifically, some relevant intermediate compounds implied in the polymer production [122] can be prepared by cyclohexane oxidation presently using $\mathrm{HNO}_{3}$. However, implementation of new more sustainable methodologies to avoid the use of highly contaminating reagents aimed also to suppress the corrosion problems constitute an urgent need.

Metal-free $\mathrm{N}$-doped nanoporous carbons prepared from MOFs can be an option for the aerobic oxidation of hydrocarbons. In this sense, Wang and Li [123] developed novel $\mathrm{N}$-doped nanoporous carbons highly graphitized from ZIF-67 to synthesize Co-based carbons which were submitted to acid treatment for Co removal. The catalysts were probed in the oxidation of cyclohexane yielding cyclohexanol-cyclohexanone mixtures and adipic acid as the major reaction products (Scheme 1). The authors found that the conversion increased almost linearly as function of the amount of graphitic nitrogen species, suggesting that the graphitic nitrogen could be a key factor in the $\mathrm{C}-\mathrm{H}$ oxidation reaction. It was also demonstrated that the reaction occurs through radical intermediate species, since it is strongly inhibited in the presence of $p$-benzoquinone as radical scavenger. $N$-doped $67-\mathrm{CN}-600$ sample was found to be a robust and recyclable catalyst in which the graphitic nitrogen remains stable during the oxidation reaction of cyclohexane. The excellent catalytic performances of these samples could be attributed to the mesoporosity together with the homogeneous distribution of doped graphitic-type nitrogen. 


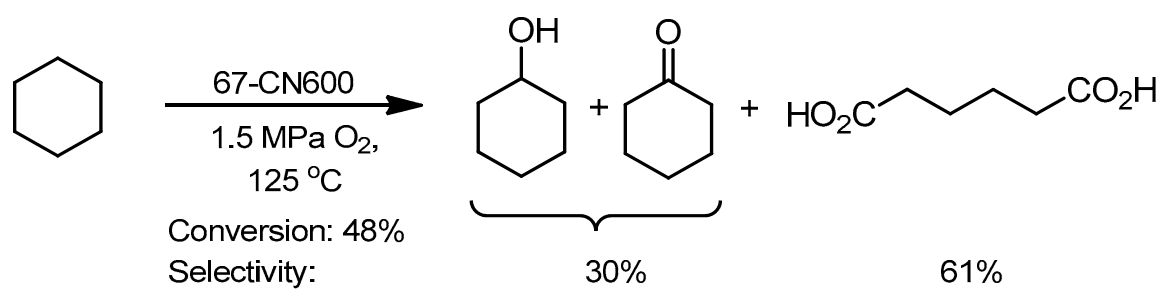

Scheme 1. Metal-free $\mathrm{N}$-doped nanoporous carbons in the aerobic oxidation of cyclohexane.

The developed methodology was also used for the aerobic oxidation of toluene and in the oxidative coupling of amines to imines. In this last case, quantitative conversions were observed leading to the corresponding benzyl imines in high yields (up to 78\%) (Scheme 2).

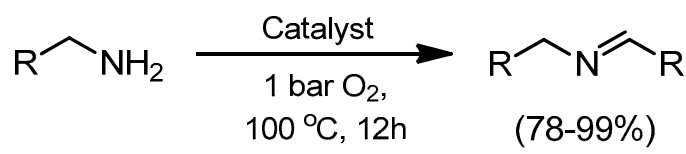

$\mathrm{R}=\mathrm{C}_{6} \mathrm{H}_{5}, \quad p-\mathrm{Me}_{-} \mathrm{C}_{6} \mathrm{H}_{4}, \quad m-\mathrm{Me}_{-} \mathrm{C}_{6} \mathrm{H}_{4}$, $o-\mathrm{Me}-\mathrm{C}_{6} \mathrm{H}_{4}, p-\mathrm{F}-\mathrm{C}_{6} \mathrm{H}_{4}, p-\mathrm{Cl}-\mathrm{C}_{6} \mathrm{H}_{4}, \mathrm{C}_{6} \mathrm{H}_{11}$, etc

Scheme 2. Metal-free $\mathrm{N}$-doped nanoporous carbons in the synthesis of benzyl imines.

Non-noble Ni-based porous carbons from direct thermolysis of Ni-MOF, formed by coordinating $\mathrm{Ni}^{\mathrm{II}}$ with 1,4-benzenedicarboxylic acid $\left(\mathrm{H}_{2} \mathrm{BDC}\right)$ and 1,4-diazabicyclo[2.2.2]octane (DABCO), involved in the selective oxidation of alkanes and ethyl benzene and related compounds have been also reported [124]. The Ni@C-N catalysts comprise Ni metallic nanoparticles (7-10 nm), highly dispersed on the carbon matrix, presenting a high degree of crystallization. The specific surface area of these materials is notably diminished $\left(100-200 \mathrm{~m}^{2} / \mathrm{g}\right)$ showing micro-/meso-/macroporosity in comparison to the parent microporous MOF (approx. $1700 \mathrm{~m}^{2} / \mathrm{g}$ ). As commented, the higher pyrolysis temperature favors both the Ni nanoparticles sinterization $(18 \mathrm{~nm})$ and the catalytic production of nanotubes, $\mathrm{Ni}$ nanoparticles acting as catalyst. In general, Ni@C-N catalysts prepared at higher temperatures showed superior catalytic performance, whereas prolonged thermolysis times produced lower catalytic activity. Thus, the best catalytic behavior in the oxidation of ethyl benzene was observed for the Ni@C-N-900-8h sample leading to acetophenone with yields between 75 and 99\% (Scheme 3).

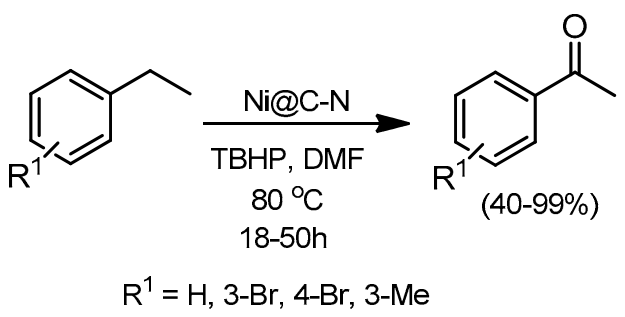

Scheme 3. Oxidation of ethyl benzene catalyzed by Ni@C-N.

Interestingly, recyclable nitrogen-cobalt catalysts prepared in one-step from ZIF-67, a cobalt-based MOF, by carbonization at different temperatures, for the selective oxidation of styrene, under aerobic conditions, has been reported (Scheme 4) [124]. The interest of this transformation is due to the importance of styrene oxide as key intermediate compound useful in pharmaceutical and agrochemical industries. This reaction often requires the use of hazardous and explosive oxidants, such as organic per-acids or peroxides, operating in the presence of highly polluting transition metal homogenous catalysts. As some Co-based MOF showed catalytic activity demonstrated in this transformation, the authors describe the preparation of nitrogen-cobalt catalysts from an inexpensive ZIF-67 presenting uniformly distributed active centers. The samples contain $\mathrm{Co}^{0}$ nanoparticles favoring the magnetically 
separation of the catalysts. While the MOF precursor is a microporous sample, the carbons ZC-600, ZC-700, ZC-800 and ZC-900 (where numbers stand for the carbonization temperature) show a mesoporous character. Catalytic performance depends on the pyrolysis temperature obtaining high conversions (76-91\%) and excellent selectivity to styrene oxide (up to $81 \%$ ). A decreased conversion was observed when using samples prepared at the highest temperatures (ZC-800 and ZC-900) probably due to the increasing $\mathrm{N}$ content.

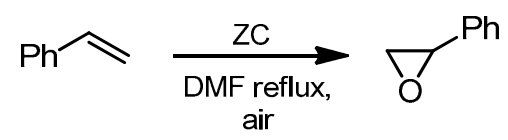

Scheme 4. Metal-free N-doped nanoporous carbons in the selective oxidation of styrene.

- Alcohol oxidation

Cost-effective, clean and selective alcohol oxidation into carbonyl compounds is considered one of the most relevant and crucial organic reactions by chemists because of its interest in the synthesis of fine chemical and for pharmaceutical industries [125]. This reaction frequently requires the use of metals, bases in excess and oxidants, and sometimes additives; noble metal catalysts being superior in terms of activity and scope of the developed methodologies. In this respect, $\mathrm{N}$-doped carbon composites $(\mathrm{Co} / \mathrm{C}-\mathrm{N})$ was also used in a base-free oxidation of primary and secondary alcohols in water under aerobic conditions [126]. Magnetic cobalt-composites were prepared by slow thermal decomposition of $\left[\mathrm{Co}_{9}(\mathrm{btc})_{6}\left(\mathrm{tpt}_{2}\right)_{2}\left(\mathrm{H}_{2} \mathrm{O}\right)_{15}\right]$ (where btc is 1,3,5-benzenetricarboxylate and tpt is 2,4,6-tris(4-pyridyl)-1,3,5-triazine), at temperatures ranging 500 to $900{ }^{\circ} \mathrm{C}$. The carbon composites are easily synthetized and separable of the reaction mixture resulting highly selective in the oxidation to ketones (Scheme 5). These materials present a good metal dispersion with Co loadings in 30-53\% range. $\mathrm{Co} / \mathrm{C}-\mathrm{N} 700$, composite prepared by heating at $700{ }^{\circ} \mathrm{C}$ resulted in the best catalytic performance for the oxidation of 1-phenylethanol, probably due to the strong basicity of this sample. The methodology reported by the authors was general, using a great variety of alcohols including alkyl and benzyl alcohols.

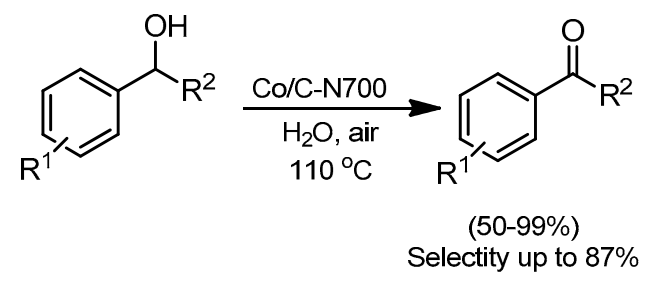

Scheme 5. Oxidation of benzyl alcohols to carbonyl compounds catalyzed by Co/C-N700 in water.

Aerobic benzyl alcohol oxidation to benzaldehyde catalyzed by $\mathrm{Cu} @ \mathrm{C}$, a copper-carbon nanocomposite, thermally synthetized from $\mathrm{Cu}_{3}(\mathrm{BTC})_{2}$, at $800{ }^{\circ} \mathrm{C}$, have been also reported [127]. During the carbonization process, $\mathrm{Cu}^{2+}$ in $\mathrm{Cu}_{3}(\mathrm{BTC})_{2}$ was transformed into $\mathrm{Cu}^{0}$ nanoparticles as demonstrated by X-ray photoelectron spectroscopy (XPS). While the MOF precursor is a microporous sample, $\mathrm{Cu} @ \mathrm{C}$ is mesoporous with $\mathrm{S}_{\mathrm{BET}}$ of $227 \mathrm{~m}^{2} / \mathrm{g}$ and pore size around of $4 \mathrm{~nm}$. The scope of the $\mathrm{Cu@C/TEMPO/NMI} \mathrm{catalytic} \mathrm{system} \mathrm{was} \mathrm{investigated} \mathrm{using} \mathrm{different} \mathrm{alcohols} \mathrm{easily} \mathrm{converted} \mathrm{into}$ the corresponding aldehydes with good to excellent yields (77-99\%).

Alcohols can be also transformed into esters, a class of valued compounds because of their use in fine chemical, natural products and polymer production and of great importance in cosmetic formulations [128]. This consists of a two-step process involving the oxidation of alcohols into the corresponding carboxylic acid followed by esterification. Zhou et al. [129] reported on the N-doped porous carbon nanocomposite prepared by thermal treatment of Co(2-Methylimidazole) 2 (ZIF-67) showing a good dispersion of Co nanoparticles $(5-20 \mathrm{~nm})$, in which $\mathrm{CoO}$ specie is part of the external surface of the nanoparticles. Pyrolysis of ZIF-67 was carried out at different temperatures, the 
NC-700-3h resulting in the best catalytic performance for the reaction between benzyl alcohol and methanol, under $\mathrm{O}_{2}$ flow and in the presence of $\mathrm{K}_{2} \mathrm{CO}_{3}$, yielding methyl benzoate with quantitative yield and total selectivity. The activity of this catalyst is attributed to the synergistic effect of both $\mathrm{Co}$ and $\mathrm{CoO}$ nanoparticles well-dispersed on the carbon matrix and accessible, but also to the pore structure which facilitate the adsorption and diffusion of the reagents limiting the metal sintering. This carbon catalyst is catalytically stable as demonstrated by reusability experiments during six consecutive cycles, showing a maintained size and shape of the nanoparticles. The scope of the methodology was investigated by using several benzyl and heterocyclic alcohols affording the corresponding esters with high yield and selectivity (Scheme 6). The authors propose the reaction mechanism depicted in Scheme 7, in which the alcohol is firstly oxidized to the corresponding aldehyde, probably by abstracting the $\beta-\mathrm{H}$ from alcohols, with formation of the corresponding hemiacetal, which is catalytically oxidized.

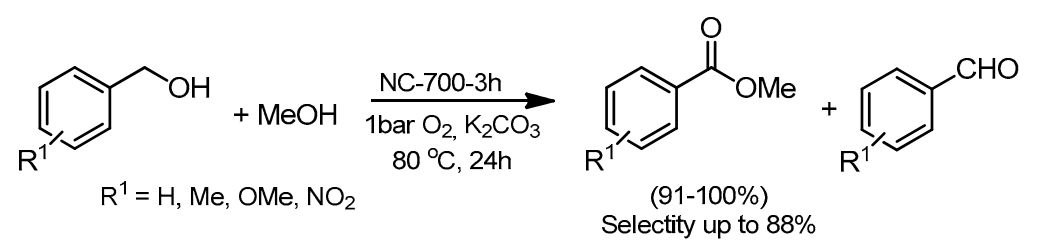

Scheme 6. Oxidation of benzyl alcohols to esters catalyzed by NC-700-3h.

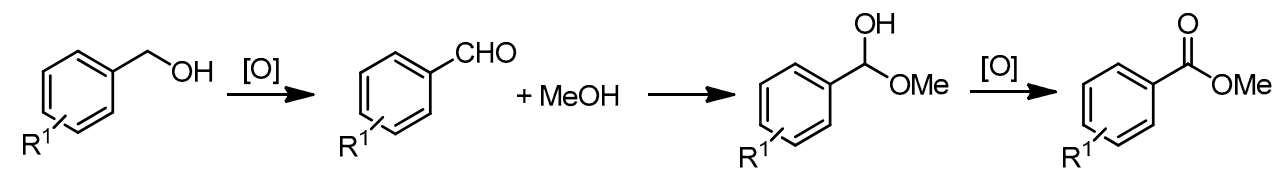

Scheme 7. Tentative mechanism for direct esterification of benzyl alcohols.

At the same time, Zhong et al. [130] reported on a base-free methodology for the alcohol oxidation to esters catalyzed by nanoscale Co-based porous carbons operating at ambient conditions. The Co@C-N catalysts were also synthetized by pyrolysis of ZIF-67 where the gradual decomposition of organic ligands (MeIM) is a determinant step in the isolation of Co nanoparticles embedded in a carbon-nitrogen matrix. The crystal size of ZIF-67 is an interesting issue in order to prepare Co@C-N particles with superior catalytic performance. The pyrolytic temperature strongly affects the yield, Co loadings and nanoparticles' dispersion (30-40 $\mathrm{wt} \%$ ), and the graphitization degree of the carbon matrix. In this sense, carbon nanotubes growth was observed when treating the MOF precursor at $900{ }^{\circ} \mathrm{C}$, favoring the aggregation of Co nanoparticles and notably decreasing the catalytic activity of the Co@CN(900) sample. The porous carbons were tested in the oxidative cross-esterification of $p$-nitrobenzyl alcohol and methanol at lower loadings, under aerobic ambient conditions, and in absence of any base or additive. The Co@C-N(800) sample resulted the best catalytic system in terms of conversion and selectivity, the catalytic activity decreasing when increasing the pyrolysis temperature observing the formation of $p$-nitrobenzaldehyde as the main reaction product. The reused catalyst Co@C-N(800) significantly loss activity but it can be regenerated by reduction $\left(\mathrm{H}_{2}, 400{ }^{\circ} \mathrm{C}, 1 \mathrm{~h}\right)$, this strongly suggesting the partial oxidation of the surface of Co nanoparticles during the reaction. The scope of the methodology is also checked when using aromatic and aliphatic alcohols yielding esters in good to excellent yields; lactones, a class of naturally-occurring natural products as flavorings, from diols were successfully prepared in high yields (Scheme 8).

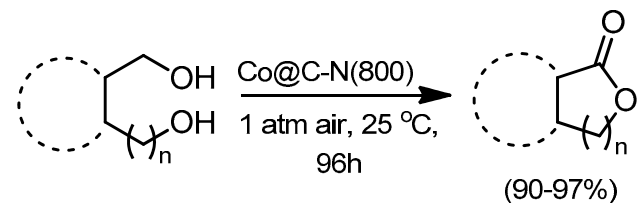

Scheme 8. Aerobic diol oxidation to lactones. 
5-Hydroxymethylfurfural (HMF) is a biomass residue easily obtained from carbohydrates as an interesting precursor of 2,5-diformylfuran (DFF), as intermediate compound useful in the synthesis of fine chemicals, pharmaceuticals and polymers, among others. However, the transformation of HMF to DFF affords great variety of oxidation products. Fang et al. [131] report a novel hollow magnetically separable porous carbons, $\mathrm{FeCo} / \mathrm{C}$, derived from a bimetallic MOF containing $\mathrm{Co}$ and $\mathrm{Fe}$ (MIL-45b), active in the selective oxidation of DFF from HMF (Scheme 9). FeCo/C materials are composed by $\mathrm{Fe}_{3} \mathrm{Co}_{7}$ phase with a high crystallization degree, when pyrolyzed at the highest temperature, but also $\mathrm{Fe}^{3+}$ and $\mathrm{Co}^{4+}$ species as demonstrated by X-ray diffraction (XRD) and XPS experiments. These materials are typically mesoporous in which the surface areas $\left(150-250 \mathrm{~m}^{2} / \mathrm{g}\right)$ and pore volumes $\left(0.31-0.85 \mathrm{~cm}^{3} / \mathrm{g}\right)$ decrease when increasing the carbonization temperature. Catalysts under study are magnetically separable and recyclable exhibiting excellent catalytic performance leading to total conversion of HMF (DFF selectivity up to 99\%), under aerobic conditions, in the presence of sodium carbonate, at $100{ }^{\circ} \mathrm{C}$, using toluene as solvent. The yield of DFF is notably influenced by the carbonization temperature during the synthesis of the carbon materials but also with the reaction temperature and $\mathrm{O}_{2}$ pressure. While the conversion of HMF increases with the reaction temperature maintaining the selectivity to DFF, selectivity strongly depends on both the temperature and $\mathrm{O}_{2}$ pressure observing the formation of the other oxidized species.

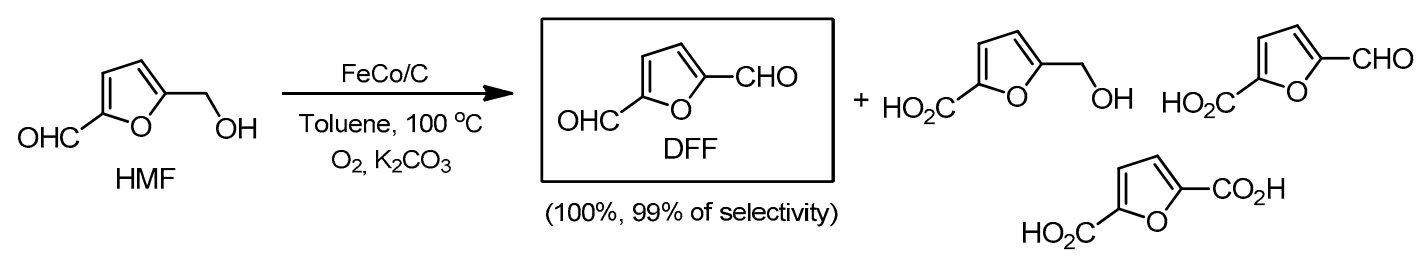

Scheme 9. Selective oxidation of 5-Hydroxymethylfurfural (HMF) to 2,5-diformylfuran (DFF) in the presence of $\mathrm{FeCo} / \mathrm{C}$ catalysts.

Different MOF-derived porous carbons have been recognized as catalysts showing a good performance for a great variety of biomass conversions such as hydrolysis of saccharide, dehydration of sugars into furan, and furans converted into fine chemicals [132].

- Oxidation of carbonyl compounds

Besides the biological importance of amide functions as part of living organisms and natural products, amides are extremely useful compounds in organic synthesis as pharmaceuticals, synthetic intermediates or even used as solvents. There are several synthetic methods to prepare amides often by activation of carboxylic acids followed by coupling with amines, characterized by using harsh reaction conditions, generation of highly polluting wastes, and also limited by readily available starting materials. In this context, Bai et al. [133] reported on the highly efficient oxidative amidation of aldehydes catalyzed by $\mathrm{N}$-doped porous carbon with embedded and highly dispersed $\mathrm{Co}$ nanoparticles $(7 \mathrm{~nm})$. Co@C-N catalyst were obtained by direct carbonization of a $\mathrm{Co}^{\mathrm{II}}$-based MOF, $\mathrm{Co}_{9}(\mathrm{btc})_{6}(\mathrm{tpt})_{2}\left(\mathrm{H}_{2} \mathrm{O}\right)_{15}$ (btc $=1,3,5$-benzenetricarboxylate and tpt $=2,4,6$-tris(4-pyridyl)-1,3,5-triazine). The amounts of Co in Co@C-N samples ranges from 30-45 wt \% as the metallic Co phase, $\mathrm{N}$ contents decrease when increasing the pyrolysis temperature (500 to $\left.900{ }^{\circ} \mathrm{C}\right)$. Co@C-N samples showed an enhancement of specific surface area (169 to $\left.251 \mathrm{~m}^{2} / \mathrm{g}\right)$ and pore volume $\left(0.08\right.$ to $\left.0.18 \mathrm{~cm}^{3} / \mathrm{g}\right)$, in comparison to the parent MOF as a non-porous structure. The porous carbons Co@C-N resulted in being highly active in oxidative amidation of different aldehydes with formamides, in the presence of TBHP using toluene as solvent, leading to the corresponding amides in good to excellent yields (Scheme 10). The authors demonstrated that the reaction proceeds following a radical pathway in which the carbonyl group remains from the aldehyde (Scheme 11). 


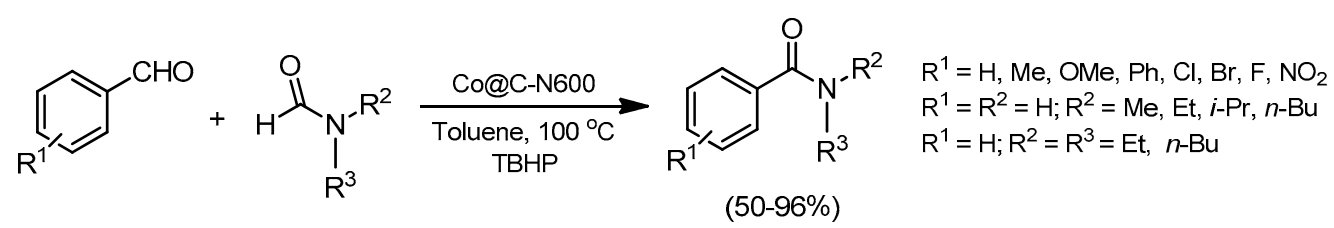

Scheme 10. Oxidative amidation of different aldehydes with formamides catalyzed by Co@C-N.

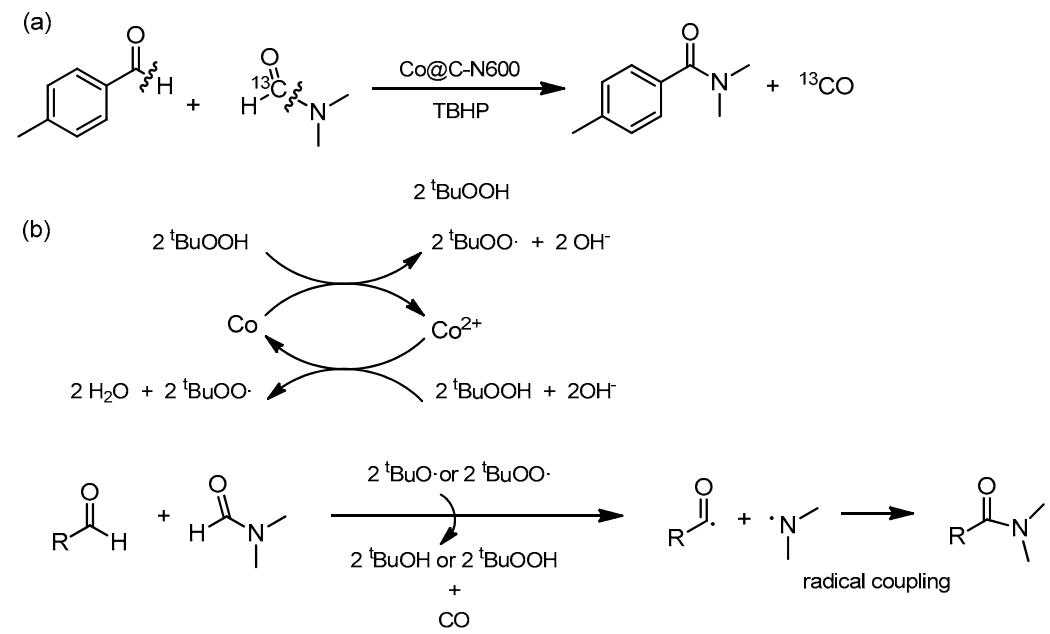

Scheme 11. Oxidative amidation of aldehydes with formamides catalyzed by Co@C-N, (a) in the presence of 13-labelled dimethylformamide; (b) proposed reaction mechanism.

- Hydrogenation reactions

Transition metal catalytic hydrogenations are transformations widely employed in the industries even using hydrogen donors such as alcohols, cyclohexene or hydrazine, under mild conditions, avoiding the use high hydrogen pressures. Porous carbons derived from MOFs have been also investigated in hydrogenation reactions of unsaturated compounds, heterocyclic systems, nitro arenes and nitriles, among others. Recently, Long et al. [134] report on a versatile non-noble Co@C-N catalyst, magnetically separable, reusable and highly efficient in the transfer hydrogenation of unsaturated compounds including hydrocarbons, carbonyl components, nitro and cyano compounds, in the presence of isopropanol as hydrogen donor, at $150{ }^{\circ} \mathrm{C}$, and in the absence of any base. The porous carbon containing metallic Co nanoparticles with a high crystallization degree was prepared by pyrolysis of $\mathrm{Co}^{\mathrm{II}}$-containing MOF, $\left[\mathrm{Co}(\mathrm{bdc})(\text { ted })_{0.5}\right] \cdot{ }_{2} \mathrm{DMF} \cdot{ }_{0.2} \mathrm{H}_{2} \mathrm{O}$ (where bdc $=$ 1,4-benzenedicarboxylic acid and ted = triethylenediamine), as sacrificial template. The parent MOF is a microporous structure; however, the Co@C-N catalysts exhibit mesoporous character, with uniform Co nanoparticles distribution sizes between 6 and $17 \mathrm{~nm}$ as function of the carbonization temperature $\left(500{ }^{\circ} \mathrm{C}\right.$ or $\left.900{ }^{\circ} \mathrm{C}\right)$. Basic properties of Co@C-N catalysts are due to the presence of nitrogen-containing species formed during the pyrolysis of triethylenediamine ligands in MOF. The hydrogenation reaction of aromatic and aliphatic ketones or aldehydes occurs with quantitative conversions and excellent selectivity (up to 90\%) even when starting from sterically hindered ketones (Scheme 12). The developed methodology has been also applied in the transfer hydrogenation of nitriles and nitro compounds by increasing the reaction temperature $\left(120\right.$ and $\left.150^{\circ} \mathrm{C}\right)$ affording the corresponding amines in good to excellent yields, avoiding the traditional methodologies in which the use of high pressures of molecular hydrogen are required. 


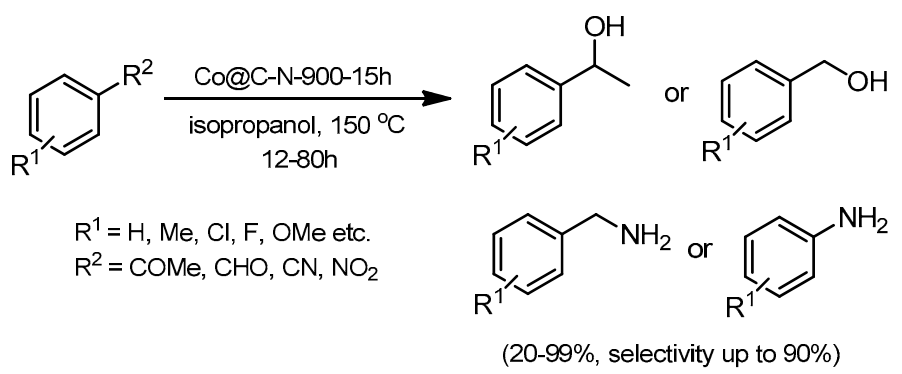

Scheme 12. Transfer hydrogenation reaction of primary and secondary alcohols, nitriles or nitro compounds.

Liu et al. [135] developed a methodology based on the use of Co@CN bi-functional nanocatalyst as active and selective catalyst in the transfer hydrogenation of cinnamaldehyde (Scheme 13). [Co(TPA)(ted $\left.)_{0.5}\right]$ (where TPA is terephthalic acid and ted 1,4-diazabicyclooctane) was used as sacrificial template by calcinating at different temperatures. Co@CN catalysts are characterized by the presence of mesoporosity and zero-valent Co nanoparticles together with high amounts of basic sites. The Co@CN catalysts resulted in very good catalytic performance in the cinamaldehyde hydrogenation in the presence of different alcohols as solvent, at $80^{\circ} \mathrm{C}$, cyclohexanol offering quantitative conversion and excellent selectivity $(99 \%)$. This methodology is also used for the transfer catalytic hydrogenation of a variety of substituted cinalmaldehydes but also acetophenones, benzaldehydes, benzylimines, nitro arenes and benzonitriles.

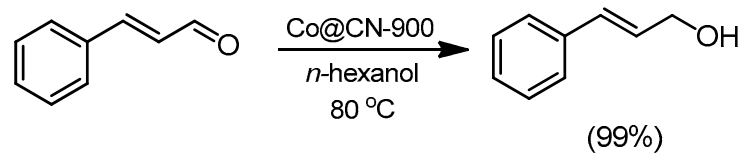

Scheme 13. Oxidation of cinnamaldehyde catalyzed by Co@CN materials.

In the same context, different synthetic strategies producing porous carbons from structurally distinct MOFs have been developed for the chemoselective hydrogenation of nitroarenes. Thus, $\mathrm{Li}$ et al. [136] report on magnetically separable catalyst comprising $\gamma-\mathrm{Fe}_{2} \mathrm{O}_{3}$ nanoparticles encapsulated in porous carbon. The catalyst was prepared by templating synthesis from microcrystals of Fe-MIL-88A, $\mathrm{Fe}_{3} \mathrm{O}(\mathrm{FA})_{3}\left(\mathrm{H}_{2} \mathrm{O}\right)_{2}\left(\mathrm{NO}_{3}\right)$ (where $\mathrm{FA}=$ fumaric acid), pyrolyzed at $500{ }^{\circ} \mathrm{C}$ during $1 \mathrm{~h}$. This porous carbon efficiently catalyzed the transfer hydrogenation of nitro compounds, in the presence of hydrazine, leading to the corresponding anilines in good to excellent yields and selectivity (Scheme 14). Niu et al. [137] also developed a $\mathrm{Cu} / \mathrm{Cu}_{2} \mathrm{O}$ porous carbon composite, from HKUST-1 $\left(\mathrm{Cu}_{3}(\mathrm{BTC})_{2}\right)$ and phenol-formaldehyde resin as a carbon source, for the selective synthesis of 4-aminophenol in the presence of $\mathrm{NaBH}_{4}$ as reducing agent.<smiles>[R]c1ccc([N+](=O)[O-])cc1</smiles>
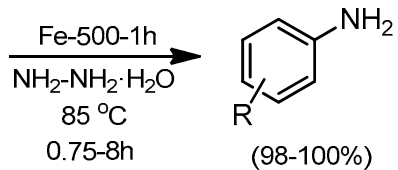

Scheme 14. Transfer hydrogenation of nitro compounds in the presence of hydrazine.

Very recently, microporous Ni-based nanocomposites, Ni@C, containing monodispersed metallic nanoparticles that were highly crystallized, were prepared and tested by Tang et al. [138]. In this case, the MOF precursor is a Ni-based MOF, in which $\mathrm{Ni}^{\mathrm{II}}$ is coordinating $p$-benzenedicarboxylic acid ligand, and carbonized at temperatures of $450,550,650$, and $750{ }^{\circ} \mathrm{C}$. The catalysts were tested in the hydrogenation of nitro compounds, leading to the corresponding amines with excellent yields (up to $93 \%$ ) and selectivity superior to $90 \%$, tolerating a great variety of functional groups. 
A more sophisticated strategy was developed by Shen et al. [139] synthetizing $N$-doped porous carbons with embedded Co@Pd core-shell nanoparticles, Co@Pd/NC, from ZIF-67 and Pd( $\left.\mathrm{NO}_{3}\right)_{2}$ as $\mathrm{Co}-\mathrm{MOF}$ and $\mathrm{Pd}$ precursors, respectively. During the thermolysis of Co-MOF at different temperatures, $\mathrm{Co}^{\mathrm{II}}$ is converted into the $\mathrm{Co}^{0}$ metallic phase giving porous carbons with different textural properties and nitrogen contents, both strongly depending of the pyrolysis temperature. The presence of $\mathrm{Pd}^{0}$ nanoparticles in Co@Pd/NC diminishes its microporosity maintaining the mesoand macroporous volume and enhancing its catalytic properties. More recently, Yang et al. [140] developed monometallic or bimetallic nanoparticles confined within hollow nitrogen-doped porous carbon capsules. Monometallic porous carbons were prepared by thermal treatment $\left(900{ }^{\circ} \mathrm{C}\right.$ under argon flow) of ZIF-8@M-TA (where M is Co or Ni) obtained from ZIF-8@K-TA material, in which potassium tannic acid (K-TA) is coated onto the ZIF-8 surface. The introduction of cobalt or niquel species was made by the replacement of $\mathrm{K}^{+}$ions by $\mathrm{Co}^{\mathrm{II}}$ or $\mathrm{Ni}^{\mathrm{II}}$. Bimetallic catalysts were synthesized decorating the ZIF surface within with platinum nanoparticles followed by coating with the tannic acid layer able to capture other metallic species, in this case cobalt or nickel, by $\mathrm{K}^{+}$ion exchange. During pyrolysis, these metal ions are reduced and can migrate to the $\mathrm{Pt}$ species originating in bimetallic alloyed nanoparticles located on the walls of carbon capsules. These bimetallic catalysts were active in the selective hydrogenation reaction of nitroarenes giving corresponding anilines with excellent conversion and selectivity, using methanol as solvent, under mild conditions $\left(50^{\circ} \mathrm{C}\right)$.

Amines have been successfully prepared from nitriles in the presence of bi-functional $\mathrm{N}$-doped Co@C catalysts, from Co-based MOF by pyrolysis at $900{ }^{\circ} \mathrm{C}$, in which $\mathrm{Co}^{0}-\mathrm{Co} \mathrm{O}^{\mathrm{II}}$ species co-exist highly dispersed on $\mathrm{N}$-doped graphitic structures [141]. The reported methodology is characterized by using isopropanol as hydrogen donor but also as solvent, at $80^{\circ} \mathrm{C}$, taking place in the absence of any base. A Co@NC-900 sample probed in a great variety of benzonitriles was found to be the most selective catalyst affording the corresponding anilines in $99 \%$ of conversion and excellent selectivity (up to $90 \%$ ), probably due to the presence of strong basic sites. Beside the reaction time, the isopropanol amount influenced the observed selectivity (Scheme 15).
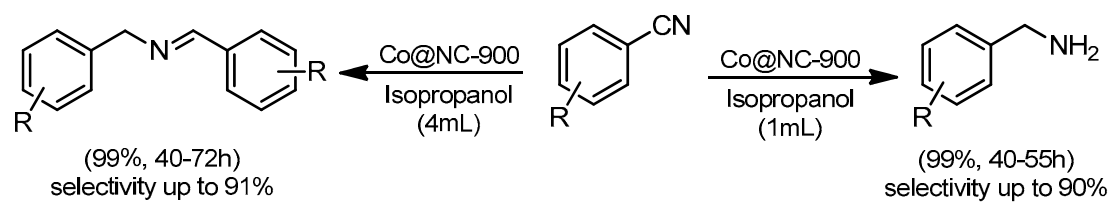

Scheme 15. Transfer hydrogenation of benzonitriles in the presence of isopropanol.

In the same context, Long et al. [142] prepared symmetrical heterometallic M-M'-MOF, $\mathrm{M}-\mathrm{M}^{\prime}(1,4-\mathrm{BDC})_{2}$ (DABCO).4DMF. $1 / 2 \mathrm{H}_{2} \mathrm{O}$ (where $\mathrm{M} / \mathrm{M}^{\prime}=\mathrm{Co}, \mathrm{Ni}, \mathrm{Cu}$ ) using a mixed-metal approach employing different metal nitrates and $\mathrm{H}_{2} \mathrm{BDC}$ and $\mathrm{DABCO}$ as chelating ligands. They were the starting points for the synthesis of multimetal MOF-derived transition metal alloy nanoparticles embedded in $\mathrm{N}$-doped carbon by thermolysis, obtaining different heterometallic carbon samples-Co-Ni@C-N, $\mathrm{Co}-\mathrm{Cu} @ \mathrm{C}-\mathrm{N}, \mathrm{Ni}-\mathrm{Cu} @ \mathrm{C}-\mathrm{N}$ and $\mathrm{Co}-\mathrm{Ni}-\mathrm{Cu} @ \mathrm{C}-\mathrm{N}$. In these cases, the carbonization process provoked the reduction of metal ions to metallic nanoparticles and significant development of the mesoporosity. A Co-Ni(3:1)@C-N sample was the most efficient catalyst with demonstrated efficiency in the transfer hydrogenation of a huge number of nitriles, in the presence of isopropanol, operating in a temperature range from $80^{\circ} \mathrm{C}$ to $120^{\circ} \mathrm{C}$, yielding the corresponding benzyl imines with excellent conversions (up to $98 \%$ ) and selectivities (up to $80 \%$ ).

Motivated by the design and applicability of new porous carbons in which single atoms of active species are present, and knowing that UiO-66, $\left(\mathrm{Zr}_{6} \mathrm{O}_{4}(\mathrm{OH})_{4}(\mathrm{BDC})_{6}\right.$ where BDC is 4-benzenedicarboxylate), is able to efficiently host $\mathrm{Ru}$ atoms, Wang et al. [143] recently reported the use of Zr-based MOFs to prepare Ru porous carbons highly active and selective in the hydrogenation of quinolines. Their studies are related to UiO-66 and the corresponding UiO-66 functionalized with ammonium, UiO-66- $\mathrm{NH}_{2}$, which by treatment with $\mathrm{RuCl}_{3}$, carbonization at $700{ }^{\circ} \mathrm{C}$ and, finally, 
$\mathrm{Zr}$ etching using HF solutions, led to the corresponding porous carbons, $\mathrm{Ru} \mathrm{SAs} / \mathrm{N}-\mathrm{C}$ and $\mathrm{Ru}$ $\mathrm{NCs} / \mathrm{C}$, respectively, presenting high surface areas (up to $1300 \mathrm{~m}^{2} / \mathrm{g}$ ). The authors demonstrated the presence of single $\mathrm{Ru}$ atoms in a Ru SAs/N-C sample, with a Ru loading of $0.30 \mathrm{wt} \%$ as $\mathrm{Ru}^{3+}$ species. The strong coordination of $\mathrm{Ru}$ to amine functions in UiO- $66-\mathrm{NH}_{2}$ is key for the development of single ruthenium sites supported on $\mathrm{N}$-doped porous carbon. However, not assisting such basic functions when using UiO-66 produces the formation of Ru aggregates as Ru clusters. High dispersion of $\mathrm{Ru}$ as single atoms in a Ru SAs/N-C sample could be responsible for the excellent conversion (99\%) and selectivity (99\%) in the quinoline reduction (Scheme 16). This methodology is also proved in the hydrogenation of other quinolines substituted at 6- or 8-positions of benzene ring, the corresponding biologically active 1,2,3,4-tetrahydro-6-hydroxyquinoline and 1,2,3,4-tetrahydro-8-hydroxyquinoline being selectively prepared.

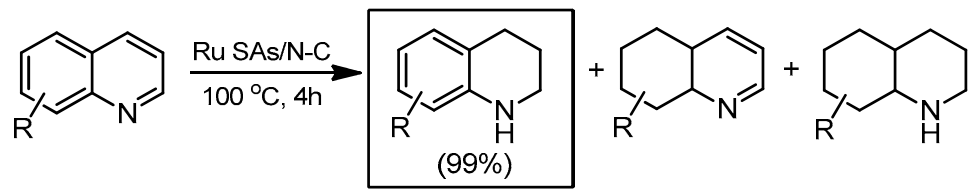

Scheme 16. Selective hydrogenation of differently substituted quinolines catalyzed by Ru SAs/N-C.

Highly efficient and selective hydrogenation of phenol to cyclohexanone catalyzed by $\mathrm{Pd}$ nanoparticles supported on a $\mathrm{N}$-doped carbon, $\mathrm{Pd} @ \mathrm{CN}$, a porous carbon derived from a Co-MOF, ZIF-67, have been also reported (Scheme 17) [144]. The synthetic approach is as follow: (1) pyrolysis of ZIF-67 at different temperatures; (2) Co nanoparticles removal in the presence of $\mathrm{HNO}_{3}$; (3) impregnation with $\mathrm{PdCl}_{2}$; and, finally, (4) carbonization at $250{ }^{\circ} \mathrm{C}$ during $3 \mathrm{~h}$, to produce $\mathrm{Pd} @ \mathrm{CN}$ catalysts in which metallic nanoparticles of $\mathrm{Pd}^{0}$ are detected. Carbon materials present a well-developed micro/mesoporosity with variable $\mathrm{N}$ contents depending on the carbonization temperature, notably influencing the catalytic performance. A Pd@CN600 sample operating under hydrogen atmosphere, at $80^{\circ} \mathrm{C}$, showed an excellent stability after reuse leading to conversion values of $95 \%$ and selectivity to cyclohexanone around $95 \%$. The excellent selectivity is related with the strong adsorption of phenol onto the $\mathrm{N}$-doped catalyst surface but also with the weak interactions of cyclohexanone.

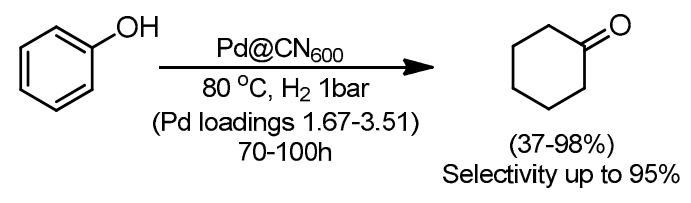

Scheme 17. Hydrogenation of phenol to cyclohexanone in the presence of a Pd@CN 600 catalyst.

The transformation of furfural to cyclopentanone have been reported in the presence of $\mathrm{CuNi}$ bimetallic nanoparticles embedded in porous carbons, CuNi@C. These materials were prepared by pyrolysis of $\mathrm{Cu}_{3}(\mathrm{BTC})_{2}$ impregnated with nickel nitrate in molar ratio of $\mathrm{Ni} / \mathrm{Cu}$ from 0 to 2.5 , at $500{ }^{\circ} \mathrm{C}$, exhibiting high catalytic activity [145]. The samples present a mesoporous character, the surface area notably decreasing when increasing the Ni/Cu ratio (from $98 \mathrm{~m}^{2} \mathrm{~g}^{-1}$ to $16 \mathrm{~m}^{2}$ $\left.\mathrm{g}^{-1}\right) . \mathrm{CuNi}_{0.5} @ \mathrm{C}$, in which $\mathrm{Cu}$ and Ni nanoparticles composed by zero-valent metals are uniformly dispersed $(15 \mathrm{~nm})$, results in the best catalytic performance yielding $99.3 \%$ of conversion with $96.9 \%$ of selectivity to cyclopentanone, operating under optimal conditions $\left(130^{\circ} \mathrm{C}, 5 \mathrm{~h}, 5 \mathrm{MPa}\right)$. The authors suggest a tentative reaction mechanism in which cylopentenone is the major intermediate compound (Scheme 18). 


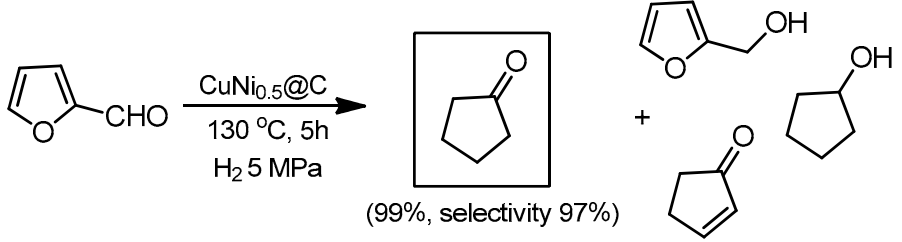

Scheme 18. Selective transformation of furfural to cyclopentanone in the presence of $\mathrm{CuNi}_{0.5} @ \mathrm{C}$ catalyst.

- Reductive amination of ketones

Compounds with amine functions are extensively used in the production of fine chemicals, since most of the drugs contain nitrogen [146,147]. This type of compounds is also widely used in material science. For instance, amino compounds play an important role as precursors of MOFs and, therefore, of $\mathrm{N}$-doped porous carbons as shown in this paper. In both senses, Co-DABCO-TPA@C-800 are composed by graphitic shell-encapsulated metallic Co nanoparticles $(5-30 \mathrm{~nm})$ and a smaller quantity of $\mathrm{Co}_{3} \mathrm{O}_{4}$ and even single $\mathrm{Co}$ atoms are supported on carbon. This porous carbon has been tested in the catalytic reductive amination of a great variety of carbonyl compounds, aldehydes and ketones, for the synthesis of the corresponding amines (Scheme 19) [148]. As mentioned above, 1,4-diazabicyclo[2.2.2]octane known as DABCO and terephthalic acid (TPA) are organic linkers coordinating cobalt in the Co-MOF precursor of the porous carbon Co-DABCO-TPA@C-800. Interestingly, the pyrolytic materials prepared from mixtures of cobalt nitrate and DABCO (Co-DABCO@C-800) or TPA (Co-TPA@C-800), both composed mainly $\mathrm{Co}_{3} \mathrm{O}_{4}$ particles with a small amount of metallic cobalt in $\mathrm{Co}-\mathrm{Co}_{3} \mathrm{O}_{4}$ core-shell structures and no single $\mathrm{Co}$ atoms or subnanometer Co structures, barely show catalytic activity. Obviously, as commented above, the pyrolysis temperature constitutes an important issue to be considered, in this case the best catalytic performance observed for the sample carbonized at $800{ }^{\circ} \mathrm{C}$. The authors carried out the selective reductive amination of aldehydes or ketones functionalized with other functional groups such as halides, esters, and $\mathrm{C}-\mathrm{C}$ double and triple bonds in the presence of $\mathrm{NH}_{3}$ (Scheme 19), amines or nitro arenes, chemo-selectively obtaining the corresponding amines with excellent yields. Additionally, the developed methodology was probed in the preparation of 10 existing drug molecules showing the applicability of this Co-based catalyst (Figure 6).

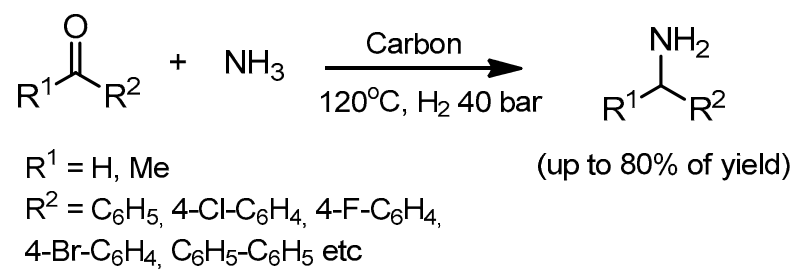

Scheme 19. Selective reductive amination of aldehydes or ketones differently substituted in the presence of $\mathrm{NH}_{3}$.<smiles>COc1cc(Br)c(OCC(C)(C)C)cc1CN1CCNCC1</smiles><smiles>CC(C)(C)c1ccc(CN2CCN(C(c3ccccc3)c3ccc(Cl)cc3)CC2)cc1</smiles><smiles>Nc1c(Br)cc(Br)cc1CNC/C=C/CO</smiles><smiles>O=C(COc1ccc(Cl)cc1)N1CCN(Cc2ccc3c(c2)OCO3)CC1</smiles>

Figure 6. Applicability of Co nanoparticles in the synthesis of existing drugs. 


\section{- Condensation reactions}

The Knoevenagel condensation reaction is considered one of the most known and extremely useful reaction in organic synthesis, allowing the synthesis of a great variety of medicinal scaffolds or relevant intermediate compounds in fine chemical synthesis, particularly for the synthesis of biologically relevant heterocyclic systems [149]. In this regard, Li et al. [150] proposed an N-doped porous carbon easily prepared by carbonization of microporous MOF-253, in which $\mathrm{Al}^{3+}$ is coordinated to 2,2'-bipyridine-5, $5^{\prime}$-dicarboxylic acid ligands, active in Knoevenagel condensation. $\mathrm{Al}^{3+}$ ions in the calcined initial MOF were removed by acid treatment yielding Cz-MOF-253 with decreased surface area as a function of the pyrolysis temperature (from $1090 \mathrm{~m}^{2} / \mathrm{g}$ to $630 \mathrm{~m}^{2} / \mathrm{g}$ ). The Lewis basicity of these materials was proved in the Knoevenagel condensation between benzaldehyde and malononitrile, demonstrating that a Cz-MOF-253-800 sample was the most basic. The scope of the reaction was investigated by using differently substituted benzaldehydes yielding the corresponding benzylidenemalononitriles with high conversion and total selectivity. A Cz-MOF-253-800 sample is able to stabilize highly dispersed ultrafine $\operatorname{Pd}^{0}$ nanoparticles $(1 \mathrm{~nm})$, by using the impregnation method followed by thermal treatment, as a heterogeneous catalyst for tandem reactions, comprising Knoevenagel condensation of benzaldehyde and malononitrile followed by $\mathrm{C}=\mathrm{C}$ bond hydrogenation reaction, leading to the corresponding nitriles in excellent yields with total selectivity $(99 \%)$ (Scheme 20).

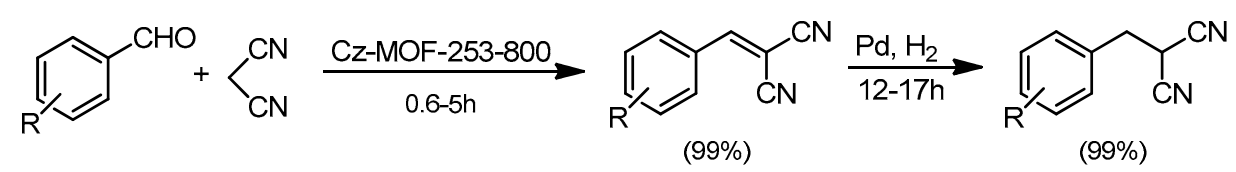

Scheme 20. Tandem reactions comprising Knoevenagel condensation of benzaldehyde and malononitrile and subsequent hydrogenation in the presence of porous carbons.

In the same way, porous carbon $\mathrm{Cu} @ \mathrm{C}$ obtained from direct carbonization of HKUST-1, $\mathrm{Cu}_{3}(\mathrm{BTC})_{2}$ was reported as highly efficient and reusable porous carbon catalyst involved in the aerobic transformation of differently substituted benzaldehydes into benzonitriles (Scheme 21) [151]. The reaction takes place in the presence of 2,2,6,6-tetramethyl-1-piperidinyloxy (TEMPO) and ammonia, under $\mathrm{O}_{2}$ atmosphere, at $70{ }^{\circ} \mathrm{C}$, giving the corresponding benzonitriles in good to excellent yields. Interestingly, this methodology has been successfully applied to the synthesis of 1-(3-fluorophenyl)-1H-pyrazole-4-carbonitrile as intermediate of LQFM 021 as a biologically active compound (Scheme 22).

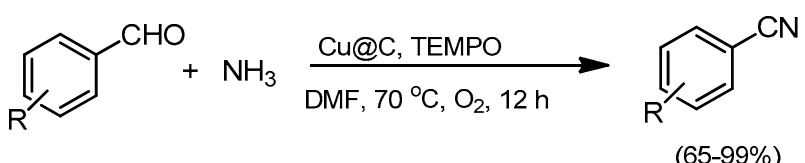

Scheme 21. Aerobic transformation of differently substituted benzaldehydes into benzonitriles catalyzed by $\mathrm{Cu} @ \mathrm{C} / \mathrm{TEMPO}$.

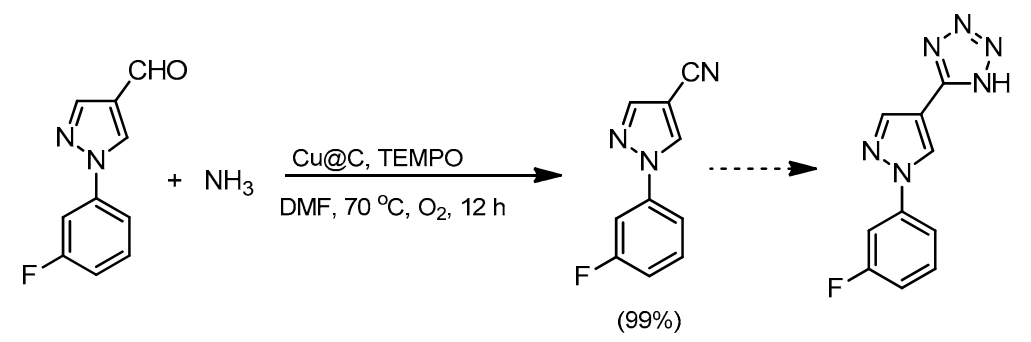

Scheme 22. Synthesis of 1-(3-fluorophenyl)-1H-pyrazole-4-carbonitrile catalyzed by Cu@C/TEMPO. 


\section{- Miscellaneous}

Some interesting transformations including alcohol dehydration, acetylene hydrochlorination and the multicomponent synthesis of amidines, all of them industrially relevant, are commented on below. In this regard, Cr-MIL-101 was used a precursor of $\mathrm{Cr}$ porous carbons implied on the dehydration of 1-phenylethanol to produce styrene, in vapor phase at $225^{\circ} \mathrm{C}$, in high conversion (99\%) (Scheme 23) [152]; styrene is an important raw material used in the production of polymers and plastics.

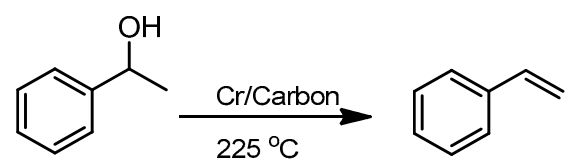

Scheme 23. Dehydration of 1-phenylethanol over $\mathrm{Cr} /$ carbon catalyst.

Metal-free nitrogen-doped porous carbon catalysts involved in synthesis of vinyl chloride, monomer involved in the polymerization process to produce polyvinyl chloride (PVC), has been also reported [153]. These materials were prepared by thermolysis of ZIF-8, at $950{ }^{\circ} \mathrm{C}$, using different amounts of melamine as an additive to optimize the nitrogen loadings. $A Z_{4} M_{1}$ sample, with a ZIF-8/melamine ratio of 4:1, showed the best specific surface area $\left(1664 \mathrm{~m}^{2} / \mathrm{g}\right)$, notably diminished for the $\mathrm{Z}_{2} \mathrm{M}_{1}, \mathrm{Z}_{4} \mathrm{M}_{3}$ and $\mathrm{Z}_{1} \mathrm{M}_{1}$ materials as resulting of the polymerized melamine coverage; higher amount of melamine originates a broader pore size distribution. The catalytic performance was assayed in a fixed reactor for acetylene hydrochlorination, at $180^{\circ} \mathrm{C}$, the $\mathrm{Z}_{4} \mathrm{M}_{1}$ catalyst leading to the highest acetylene conversion (60\%) showing a slightly diminished catalytic activity after $50 \mathrm{~h}$. This is probably due to deactivation by coke deposition, deactivation of the catalysts increasing with the nitrogen content. More recently, Chao et al. [154] probed metal-free nitrogen-doped porous carbon by direct pyrolysis of $\mathrm{ZIF}-8$, at $1000{ }^{\circ} \mathrm{C}\left(\mathrm{C}-\mathrm{N}_{2}\right)$, but also under ammonia atmosphere $\left(\mathrm{C}-\mathrm{NH}_{3}\right)$, with the aim of expanding the micropore size distribution. $\mathrm{C}-\mathrm{NH}_{3}$ sample exhibited microporous character with the highest surface area (1166 compared $875 \mathrm{~m}^{2} / \mathrm{g}$ for $\mathrm{C}-\mathrm{N}_{2}$ sample) but similar nitrogen loadings $\left(\mathrm{C}-\mathrm{N}_{2}=6.28 \% \mathrm{C}-\mathrm{NH}_{3}=4.59 \%\right)$ although presenting different $\mathrm{N}$ species ratios. In this sense, the $\mathrm{C}-\mathrm{NH}_{3}$ catalyst showed the best catalytic performance yielding high conversion of acetylene (92\%) and high durability, probably attributed to the porosity of the carbon and $\mathrm{N}$ functions.

Interestingly, copper carbon from $\mathrm{Cu}_{3}(\mathrm{BTC})_{2}$ able to catalyze the highly selective three-component coupling reaction for the synthesis of a great variety of $\mathrm{N}$-sulfonyl amidines in good to excellent yields (up to 83\%) has been reported [155] (Scheme 24). Cu@C catalyst was recycled during three consecutive cycles without significant activity loss.

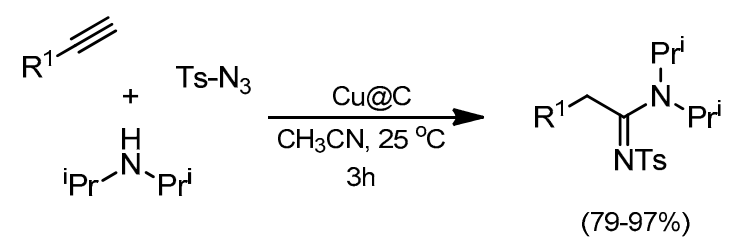

Scheme 24. Selective three-component coupling reaction for the synthesis of N-Sulfonyl amidines.

\section{Porous Carbon from COFs in Fine Chemical Synthesis}

COFs have been primarily developed for applications in gas storage or in the energy area. For this reason, much work has been done in such applications, and most of the material development is focused on new microporous structures with high surface areas and porous volumes along with tailored incorporation of heteroatoms. Nevertheless, some examples can be found on the use of these type of materials in catalysis $[67,72,93]$.

COF-derived porous carbons have recently started to gain attention as catalysts due to not only their textural properties but also to the ability to introduce different dopant atoms in tailored amounts 
and positions as mentioned. This is particularly interesting in metal-free catalysis in the effort to understand the role of these dopants. However, very few reports can be found on fine chemical synthesis, as this is still a very new and exciting field of application yet to be further explored.

$\mathrm{Li}$ et al. [156] reported the use of $B, N$-doped hierarchical hollow carbon spheres derived from the pyrolysis of COFs as metal-free catalysts in nitroarene reduction. Full conversion of nitrobenzene and quantitative selectivity of aniline can be achieved in $3 \mathrm{~h}$, at $100{ }^{\circ} \mathrm{C}$, in the presence of hydrazine ethanol solution as hydrogen donor. The catalyst was reused without loss of activity for 10 consecutive runs maintaining its structural stability and morphology. Based on the theoretical and experimental studies, the authors propose that the boron atoms situated at meta-position to pyridinic $\mathrm{N}$ atoms can be identified as the main catalytically active sites.

Via direct carbonization of 2D COF materials, Hu et al. [157] successfully fabricated mesoporous carbon materials with high $\mathrm{N}$ content. The authors used an available and cheap piperazine and cyanuric chloride as building blocks to prepare the 2D COF. After pyrolysis of the COF precursor at a series of temperatures $\left(500,600,700\right.$, and $\left.800{ }^{\circ} \mathrm{C}\right)$, the catalysts obtained were tested in the hydrogenation of nitroarenes reaction and in Knoevenagel condensation of aromatic aldehyde derivatives in aqueous solution. The catalyst prepared at $700{ }^{\circ} \mathrm{C}$ presented very catalytic performance in both hydrogenation of nitroarenes and Knoevenagel condensation. For example, benzylidenemalononitrile was obtained with almost full conversion and excellent selectivity within $1 \mathrm{~h}$ under mild conditions. The authors concluded that the graphitic $\mathrm{N}$ and its related defects in the catalysts are the critical factors of high catalytic activity and are probably the main active sites.

Carbon-supported metal catalyst are well known and used in several catalytic reactions. On the other hand, hollow carbon spheres (HCS) are very attractive hollow-structured porous materials due to features such as low density, good thermal stability, and high permeability. This carbon spheres have been considered as nanoreactors by encapsulating catalytically active metal nanoparticles (NPs). Chen et al. [100] reported a method that allowed for the in situ encapsulation of metal nanoparticles into N-doped hollow carbon spheres (NHCS). The procedure involved the controlled carbonization process of COFs doped with metal cations as precursors. The Pd catalysts obtained (Pd@NHCS) were tested in the hydrogenation of nitrobenzene in ethanol and oxidation of cinnamyl alcohol and revealed high catalytic activity and selectivity, out-performing the commercial $\mathrm{Pd} / \mathrm{C}$ catalysts. The enhancement in performance was attributed to the combined effect of structure, high metal dispersion and uniform $\mathrm{N}$ doping of the carbon material.

\section{Conclusions and Perspectives}

Concerns regarding environmental sustainability in terms of energy storage and chemical production have led the scientific community to the rapid development of new advanced materials with great potential, an area in the frontier of several research disciplines. Nowadays, MOFs and COFs can be considered green materials for a more sustainable future, conditioned to synthetic availability and manufacturing procedures for large-scale production, although some of them are already commercialized. During the last decades, a lot of efforts have been made all of which address the development of a great molecular diversity of MOF, considering a large variety of organic ligands and metal ions. However, environmental challenges including the use of safe and biocompatible building blocks if possible, water reaction media or solvent-free strategies [158] low energy costs, manufacture in continuous and even the theoretical rational design of MOF for a specific use are still required [159]. Nevertheless, MOF-based materials present relatively low stability which limits specifically their application in catalysis.

In this context, it is well-known that porous carbons have been used for a long time as catalysts and supports, demonstrating their efficiency as versatile materials for sustainable catalytic applications. In fact, porous carbons emerge as more robust catalytic systems alternative to metal organic networks [160]. Interesting overviews regarding porous carbons and metal-supported carbon-based materials applied in fine chemical synthesis have been reported recently $[7,152]$. To date, 
ACs are special protagonists as economical alternative to other solid catalysts in the production of valuable compounds.

In the last decades, the spectacular development of material science has allowed the knowledge of new synthetic strategies aimed to improve the physico-chemical and textural properties of more sophisticated functional nanostructured materials, carbon materials among them. In competition with traditional porous carbons, MOF- and COF-derived carbons with ultra-high surface areas, large pore volumes and abundant metal/organic species or doping heteroatoms appear as opportunities in various research fields. However, knowledge of the catalytic behavior of this type of carbons in the synthesis of fine chemicals is still in its infancy, mainly limited to a few liquid-phase reactions mostly including oxidations and hydrogenations reactions and basic condensation reactions. On this basis, the unique properties of these materials open the doors, in the nearest future, to the application of a new generation of carbons with highly developed porosity catalyzing interesting organic transformations based on an aldol reaction for the synthesis of relevant heterocyclic scaffolds [161].

One of the major challenges in the development of metal-supported carbons is to favor the high dispersion of active metal nanoparticles to minimize their agglomeration and sintering. In fact, all the factors which allow good accessibility to reactants and products into the active centers strongly influence the catalytic performance in such a manner that metal loadings, dispersion, and location of metal nanoparticles on the catalyst surface are important issues to be considered. The small-size limit of the metal particles acquires a supreme importance in conditioning the catalytic performance [162]. In this context, the development of the single-atom carbon catalysts constituted by isolated metal atoms at sub-nanometer scale, highly dispersed on the surface, results in notably enhanced catalytic performances and selectivity representing a new concept and a true challenge in material science [163]. MOFs then emerge as enabling metal-based materials for the single-atom porous carbon catalysts synthesis under carefully and strictly controlled synthesis conditions. The high dispersion of metallic species in MOF precursors together with the appropriate thermal treatment seems to be crucial in the preparation of these fascinating porous carbons, in which the presence of single-atoms of metallic species has been demonstrated. Remarkably, this arrangement cannot be easily performed by using traditional post-synthetic methods.

The MOF-templated approach represents, then, a new practical synthetic strategy to obtain advanced carbon-based nanomaterials including metal-free porous carbons with unique multidimensional structures, enhanced durability, suitable for functionalization and exhibiting comparable or even improved catalytic performances than noble metal-based catalysts. In fact, this approach allows the synthesis of strongly basic $N$-doped porous carbons, highly graphitized, with notably high $\mathrm{N}$ contents, superior to those prepared by conventional methods. Analogously, the use of COFs allows the preparation of heteroatom-doped porous carbons in which heteroatoms are homogenously distributed on the surface with enhanced acid-base properties. This results in an interesting opportunity for this kind of materials, porous carbons from MOFs and COFs, in the development of catalytic processes involved in fine chemical synthesis and a challenge for the development of basic catalysis until now scarce.

The knowledge of the reaction mechanism for porous carbon formation as function of carbonization temperature constitutes also an important topic to be studied. Aimed at that, some mechanistic hints have been reported, the pyrolysis of MOFs firstly starting with water molecules desorption, disintegration of the framework by releasing $\mathrm{CO}_{\mathrm{x}}$, aromatics and hydrocarbons until metal oxide formation. In this context, real-time monitoring by using Raman spectroscopy should provide valuable information concerning the birth and evolution of the porous structure of these materials [164].

Author Contributions: The authors individual contribution is as follow: conceptualization, E.P.-M. and I.M.; methodology, E.P.-M., I.M. and M.B.; resources, E.P.-M., I.M., M.B. and I.M.F.; writing-original draft preparation, E.P.-M., I.M., M.B. and I.M.F.; writing—review and editing, E.P.-M., I.M., M.B. and I.F.; supervision, E.P.-M. and I.M. 
Funding: This work has been supported by Spanish Ministry (CTM 2014-56668-R project) and the Associate Laboratory for Green Chemistry-LAQV which is financed by national funds from FCT/MCTES (UID/QUI/50006/2013) and co-financed by the ERDF under the PT2020 Partnership Agreement (POCI-01-0145-FEDER-007265). Ines Matos thanks FCT for the Investigator FCT contract IF/01242/2014/CP1224/CT0008 and M. Bernardo for post-doc fellowship (SFRH/BPD/93407/2013). Inês Matos also thanks Fundacion Carolina.

Conflicts of Interest: The authors declare no conflict of interest.

\section{References}

1. Bagheri, S.; Muhd Julkapli, N.; Bee Abd Hamid, S. Functionalized activated carbon derived from biomass for photocatalysis applications perspective. Int. J. Photoenergy 2015, 2015, 218743. [CrossRef]

2. Benzigar, M.R.; Talapaneni, S.N.; Joseph, S.; Ramadass, K.; Singh, G.; Scaranto, J.; Ravon, U.; Al-Bahily, K.; Vinu, A. Recent advances in functionalized micro and mesoporous carbon materials: Synthesis and applications. Chem. Soc. Rev. 2018, 47, 2680-2721. [CrossRef] [PubMed]

3. Yang, Y.; Chiang, K.; Burke, N. Porous carbon-supported catalysts for energy and environmental applications: A short review. Catal. Today 2011, 178, 197-205. [CrossRef]

4. Borchardt, L.; Zhu, Q.L.; Casco, M.E.; Berger, R.; Zhuang, X.; Kaskel, S.; Feng, X.; Xu, Q. Toward a molecular design of porous carbon materials. Mater. Today 2017, 20, 592-610. [CrossRef]

5. Maneerung, T.; Liew, J.; Dai, Y.; Kawi, S.; Chong, C.; Wang, C.H. Activated carbon derived from carbon residue from biomass gasification and its application for dye adsorption: Kinetics, isotherms and thermodynamic studies. Bioresour. Technol. 2016, 200, 350-359. [CrossRef] [PubMed]

6. Ring, K.; DeGuzman, M. Activated Carbon, Chemical Economics Handbook; IHS Markit: London, UK, 2017.

7. Matos, I.; Bernardo, M.; Fonseca, I. Porous carbon: A versatile material for catalysis. Catal. Today 2017, 285, 194-203. [CrossRef]

8. Daud, W.M.A.W.; Houshamnd, A.H. Textural characteristics, surface chemistry and oxidation of activated carbon. J. Nat. Gas Chem. 2010, 19, 267-279. [CrossRef]

9. Jaramillo, J.; Álvarez, P.M.; Gómez-Serrano, V. Oxidation of activated carbon by dry and wet methods surface chemistry and textural modifications. Fuel Process. Technol. 2010, 91, 1768-1775. [CrossRef]

10. Marsh, H.; Rodríguez-Reinoso, F. Characterization of Activated Carbon. In Activated Carbon; Elsevier: Kidlington, UK, 2006; Volume 18, pp. 143-242. ISBN 9780080444635.

11. Thommes, M.; Kaneko, K.; Neimark, A.V.; Olivier, J.P.; Rodriguez-reinoso, F.; Rouquerol, J.; Sing, K.S.W. Physisorption of gases, with special reference to the evaluation of surface area and pore size distribution (IUPAC Technical Report). Pure Appl. Chem. 2015, 87, 1051-1069. [CrossRef]

12. Group, F. Adsorption; CRC Press: Boca Raton, FL, USA, 2005; ISBN 9780824753443.

13. Libbrecht, W.; Verberckmoes, A.; Thybaut, J.W.; Van Der Voort, P.; De Clercq, J. Soft templated mesoporous carbons: Tuning the porosity for the adsorption of large organic pollutants. Carbon N. Y. 2017, 116, 528-546. [CrossRef]

14. Enterría, M.; Figueiredo, J.L. Nanostructured mesoporous carbons: Tuning texture and surface chemistry. Carbon N. Y. 2016, 108, 79-102. [CrossRef]

15. Figueiredo, J.L. Functionalization of porous carbons for catalytic applications. J. Mater. Chem. A 2013, 1, 9351. [CrossRef]

16. Matos, I.; Neves, P.D.; Castanheiro, J.E.; Perez-Mayoral, E.; Martin-Aranda, R.; Duran-Valle, C.; Vital, J.; Botelho Do Rego, A.M.; Fonseca, I.M. Mesoporous carbon as an efficient catalyst for alcoholysis and aminolysis of epoxides. Appl. Catal. A Gen. 2012, 439-440, 24-30. [CrossRef]

17. Matos, I.; Fernandes, S.; Guerreiro, L.; Barata, S.; Ramos, A.M.; Vital, J.; Fonseca, I.M. The effect of surfactants on the porosity of carbon xerogels. Microporous Mesoporous Mater. 2006, 92, 38-46. [CrossRef]

18. Chingombe, P.; Saha, B.; Wakeman, R.J. Surface modification and characterisation of a coal-based activated carbon. Carbon N. Y. 2005, 43, 3132-3143. [CrossRef]

19. Gorgulho, H.F.; Mesquita, J.P.; Gonçalves, F.; Pereira, M.F.R.; Figueiredo, J.L. Characterization of the surface chemistry of carbon materials by potentiometric titrations and temperature-programmed desorption. Carbon N. Y. 2008, 46, 1544-1555. [CrossRef]

20. Marsh, H.; Rodríguez-Reinoso, F. Activated Carbon; Elsevier: Kidlington, UK, 2006; ISBN 9780080444635.

21. Activated Carbon Producers Association: Brussels, Belgium. ACPA Activated Carbon Producers Association, Brussels, Belgium. Available online: http:/ / acpa.cefic.org/index.php (accessed on 28 November 2018). 
22. Yahya, M.A.; Al-Qodah, Z.; Ngah, C.W.Z. Agricultural bio-waste materials as potential sustainable precursors used for activated carbon production: A review. Renew. Sustain. Energy Rev. 2015, 46, 218-235. [CrossRef]

23. Canales-Flores, R.A.; Prieto-García, F. Activation Methods of Carbonaceous Materials Obtained from Agricultural Waste. Chem. Biodivers. 2016, 13, 261-268. [CrossRef]

24. González-García, P. Activated carbon from lignocellulosics precursors: A review of the synthesis methods, characterization techniques and applications. Renew. Sustain. Energy Rev. 2018, 82, 1393-1414. [CrossRef]

25. Hadi, P.; Xu, M.; Ning, C.; Sze Ki Lin, C.; McKay, G. A critical review on preparation, characterization and utilization of sludge-derived activated carbons for wastewater treatment. Chem. Eng. J. 2015, 260, 895-906. [CrossRef]

26. Saleh, T.A.; Gupta, V.K. Processing methods, characteristics and adsorption behavior of tire derived carbons: A review. Adv. Colloid Interface Sci. 2014, 211, 93-101. [CrossRef] [PubMed]

27. Tan, X.; Liu, S.; Liu, Y.; Gu, Y.; Zeng, G.; Hu, X.; Wang, X.; Liu, S.; Jiang, L. Biochar as potential sustainable precursors for activated carbon production: Multiple applications in environmental protection and energy storage. Bioresour. Technol. 2017, 227, 359-372. [CrossRef] [PubMed]

28. Kim, H.S.; Kang, M.S.; Yoo, W.C. Highly Enhanced Gas Sorption Capacities of N-Doped Porous Carbon Spheres by Hot $\mathrm{NH}_{3}$ and $\mathrm{CO}_{2}$ Treatments. J. Phys. Chem. C 2015, 119, 28512-28522. [CrossRef]

29. Xiong, Z.; Shihong, Z.; Haiping, Y.; Tao, S.; Yingquan, C.; Hanping, C. Influence of $\mathrm{NH}_{3} / \mathrm{CO}_{2}$ Modification on the Characteristic of Biochar and the $\mathrm{CO}_{2}$ Capture. BioEnergy Res. 2013, 6, 1147-1153. [CrossRef]

30. Zhang, X.; Zhang, S.; Yang, H.; Feng, Y.; Chen, Y.; Wang, X.; Chen, H. Nitrogen enriched biochar modified by high temperature $\mathrm{CO}_{2}$-ammonia treatment: Characterization and adsorption of $\mathrm{CO}_{2}$. Chem. Eng. J. 2014, 257, 20-27. [CrossRef]

31. Wachowski, L.; Hofman, M. Thermogravimetric and textural studies of modified carbonaceous materials. Thermochim. Acta 2005, 437, 82-86. [CrossRef]

32. Jain, A.; Balasubramanian, R.; Srinivasan, M.P. Hydrothermal conversion of biomass waste to activated carbon with high porosity: A review. Chem. Eng. J. 2016, 283, 789-805. [CrossRef]

33. Hu, B.; Wang, K.; Wu, L.; Yu, S.-H.; Antonietti, M.; Titirici, M.-M. Engineering Carbon Materials from the Hydrothermal Carbonization Process of Biomass. Adv. Mater. 2010, 22, 813-828. [CrossRef]

34. Titirici, M.-M.; Antonietti, M.; Baccile, N. Hydrothermal carbon from biomass: A comparison of the local structure from poly- to monosaccharides and pentoses/hexoses. Green Chem. 2008, 10, 1204. [CrossRef]

35. Sevilla, M.; Fuertes, A.B. Chemical and Structural Properties of Carbonaceous Products Obtained by Hydrothermal Carbonization of Saccharides. Chem. A Eur. J. 2009, 15, 4195-4203. [CrossRef]

36. Sevilla, M.; Fuertes, A.B. The production of carbon materials by hydrothermal carbonization of cellulose. Carbon N. Y. 2009, 47, 2281-2289. [CrossRef]

37. Kambo, H.S.; Dutta, A. A comparative review of biochar and hydrochar in terms of production, physico-chemical properties and applications. Renew. Sustain. Energy Rev. 2015, 45, 359-378. [CrossRef]

38. Montané, D.; Fierro, V.; Marêché, J.-F.; Aranda, L.; Celzard, A. Activation of biomass-derived charcoal with supercritical water. Microporous Mesoporous Mater. 2009, 119, 53-59. [CrossRef]

39. Fujino, T. Phase and structural change of carbonized wood materials by hydrothermal treatment. Solid State Ion. 2002, 151, 197-203. [CrossRef]

40. Salvador, F.; Sánchez-Montero, M.J.; Izquierdo, C. C/ $\mathrm{H}_{2} \mathrm{O}$ Reaction under Supercritical Conditions and Their Repercussions in the Preparation of Activated Carbon. J. Phys. Chem. C 2007, 111, 14011-14020. [CrossRef]

41. Yan, H.; Li, Y.; Guo, X.; Zhou, M.; Wang, H.-Q.; Dai, Y.; Zheng, J.-C. Synergistic Supercritical Water 'Wet' Activated Biomass Carbon as High Performances Electrode Materials for Supercapacitor. J. Electrochem. Soc. 2018, 165, A2075-A2083. [CrossRef]

42. Lachos-Perez, D.; Brown, A.B.; Mudhoo, A.; Timko, M.T.; Rostagno, M.A.; Forster-Carneiro, T. Applications of subcritical and supercritical water conditions for extraction, hydrolysis, gasification, and carbonization of biomass: A critical review. Biofuel Res. J. 2017, 4, 611-626. [CrossRef]

43. Inagaki, M.; Park, K.C.; Endo, M. Carbonization under pressure. New Carbon Mater. 2010, 25, 409-420. [CrossRef]

44. Quesada-Plata, F.; Ruiz-Rosas, R.; Morallón, E.; Cazorla-Amorós, D. Activated Carbons Prepared through H3PO4 -Assisted Hydrothermal Carbonisation from Biomass Wastes: Porous Texture and Electrochemical Performance. ChemPlusChem 2016, 81, 1349-1359. [CrossRef] 
45. Jain, A.; Balasubramanian, R.; Srinivasan, M.P. Tuning hydrochar properties for enhanced mesopore development in activated carbon by hydrothermal carbonization. Microporous Mesoporous Mater. 2015, 203, 178-185. [CrossRef]

46. Fechler, N.; Wohlgemuth, S.-A.; Jäker, P.; Antonietti, M. Salt and sugar: Direct synthesis of high surface area carbon materials at low temperatures via hydrothermal carbonization of glucose under hypersaline conditions. J. Mater. Chem. A 2013, 1, 9418. [CrossRef]

47. Ao, W.; Fu, J.; Mao, X.; Kang, Q.; Ran, C.; Liu, Y.; Zhang, H.; Gao, Z.; Li, J.; Liu, G.; et al. Microwave assisted preparation of activated carbon from biomass: A review. Renew. Sustain. Energy Rev. 2018, 92, 958-979. [CrossRef]

48. Yuen, F.K.; Hameed, B.H. Recent developments in the preparation and regeneration of activated carbons by microwaves. Adv. Colloid Interface Sci. 2009, 149, 19-27. [CrossRef] [PubMed]

49. Rojas-Cervantes, M.L. Some strategies to lower the production cost of carbon gels. J. Mater. Sci. 2015, 50, 1017-1040. [CrossRef]

50. Rey-Raap, N.; Arenillas, A.; Menéndez, J.A. Carbon Gels and Their Applications: A Review of Patents. In Submicron Porous Materials; Springer: Cham, Switzerland, 2017; pp. 25-52.

51. White, R.J.; Brun, N.; Budarin, V.L.; Clark, J.H.; Titirici, M.M. Always look on the "light" side of life: Sustainable carbon aerogels. ChemSusChem 2014, 7, 670-689. [CrossRef] [PubMed]

52. Brun, N.; García-González, C.A.; Smirnova, I.; Titirici, M.M. Hydrothermal synthesis of highly porous carbon monoliths from carbohydrates and phloroglucinol. RSC Adv. 2013, 3, 17088. [CrossRef]

53. Lee, J.; Kim, J.; Hyeon, T. Recent Progress in the Synthesis of Porous Carbon Materials. Adv. Mater. 2006, 18, 2073-2094. [CrossRef]

54. Zhang, X.; Li, W.; Lu, A. Designed porous carbon materials for efficient $\mathrm{CO}_{2}$ adsorption and separation. New Carbon Mater. 2015, 30, 481-501. [CrossRef]

55. Chuenchom, L.; Kraehnert, R.; Smarsly, B.M. Recent progress in soft-templating of porous carbon materials. Soft Matter 2012, 8, 10801. [CrossRef]

56. Dutta, S.; Bhaumik, A.; Wu, K.C.W. Hierarchically porous carbon derived from polymers and biomass: Effect of interconnected pores on energy applications. Energy Environ. Sci. 2014, 7, 3574-3592. [CrossRef]

57. Stock, N.; Biswas, S. Synthesis of Metal-Organic Frameworks (MOFs): Routes to Various MOF Topologies, Morphologies, and Composites. Chem. Rev. 2012, 112, 933-969. [CrossRef] [PubMed]

58. Furukawa, H.; Cordova, K.E.; O'Keeffe, M.; Yaghi, O.M. The Chemistry and Applications of Metal-Organic Frameworks. Science 2013, 341, 1230444. [CrossRef] [PubMed]

59. Férey, G. Hybrid porous solids: Past, present, future. Chem. Soc. Rev. 2008, 37, 191-214. [CrossRef] [PubMed]

60. Wen, Y.; Zhang, J.; Xu, Q.; Wu, X.T.; Zhu, Q.L. Pore surface engineering of metal-organic frameworks for heterogeneous catalysis. Coord. Chem. Rev. 2018, 376, 248-276. [CrossRef]

61. Li, J.-R.; Ma, Y.; McCarthy, M.C.; Sculley, J.; Yu, J.; Jeong, H.-K.; Balbuena, P.B.; Zhou, H.-C. Carbon dioxide capture-related gas adsorption and separation in metal-organic frameworks. Coord. Chem. Rev. 2011, 255, 1791-1823. [CrossRef]

62. Fang, Y.; Ma, Y.; Zheng, M.; Yang, P.; Asiri, A.M.; Wang, X. Metal-organic frameworks for solar energy conversion by photoredox catalysis. Coord. Chem. Rev. 2018, 373, 83-115. [CrossRef]

63. Yin, P.; Yao, T.; Wu, Y.; Zheng, L.; Lin, Y.; Liu, W.; Ju, H.; Zhu, J.; Hong, X.; Deng, Z.; et al. Single Cobalt Atoms with Precise N-Coordination as Superior Oxygen Reduction Reaction Catalysts. Angew. Chem. Int. Ed. 2016, 55, 10800-10805. [CrossRef]

64. Liu, J.; Chen, L.; Cui, H.; Zhang, J.; Zhang, L.; Su, C.-Y. Applications of metal-organic frameworks in heterogeneous supramolecular catalysis. Chem. Soc. Rev. 2014, 43, 6011-6061. [CrossRef]

65. Jiang, D.; Xu, P.; Wang, H.; Zeng, G.; Huang, D.; Chen, M.; Lai, C.; Zhang, C.; Wan, J.; Xue, W. Strategies to improve metal organic frameworks photocatalyst's performance for degradation of organic pollutants. Coord. Chem. Rev. 2018, 376, 449-466. [CrossRef]

66. Khan, N.A.; Hasan, Z.; Jhung, S.H. Beyond pristine metal-organic frameworks: Preparation and application of nanostructured, nanosized, and analogous MOFs. Coord. Chem. Rev. 2018, 376, 20-45. [CrossRef]

67. Díaz, U.; Corma, A. Ordered Covalent Organic Frameworks, COFs and PAFs. From Preparation to Application; Elsevier: New York, NY, USA, 2016; Volume 311, pp. 85-124.

68. Ding, S.Y.; Wang, W. Covalent organic frameworks (COFs): From design to applications. Chem. Soc. Rev. 2013, 42, 548-568. [CrossRef] [PubMed] 
69. Waller, P.J.; Gándara, F.; Yaghi, O.M. Chemistry of Covalent Organic Frameworks. Acc. Chem. Res. 2015, 48, 3053-3063. [CrossRef] [PubMed]

70. Ding, S.Y.; Gao, J.; Wang, Q.; Zhang, Y.; Song, W.G.; Su, C.Y.; Wang, W. Construction of covalent organic framework for catalysis: Pd/COF-LZU1 in Suzuki-Miyaura coupling reaction. J. Am. Chem. Soc. 2011, 133, 19816-19822. [CrossRef] [PubMed]

71. Lucovsky, G.; Rayner, B.; Zhang, Y.; Whitten, J. Experimental determination of band offset energies between Zr silicate alloy dielectrics and crystalline Si substrates by XAS, XPS and AES and ab initio theory: A new approach to the compositional dependence of direct tunneling currents. In Proceedings of the Digest. International Electron Devices Meeting, San Francisco, CA, USA, 8-11 December 2002; Volume 227, pp. 617-620. [CrossRef]

72. Hu, H.; Yan, Q.; Ge, R.; Gao, Y. Covalent organic frameworks as heterogeneous catalysts. Chin. J. Catal. 2018, 39, 1167-1179. [CrossRef]

73. Sun, J.K.; Xu, Q. Functional materials derived from open framework templates/precursors: Synthesis and applications. Energy Environ. Sci. 2014, 7, 2071-2100. [CrossRef]

74. Matsuyama, K. Supercritical fluid processing for metal-organic frameworks, porous coordination polymers, and covalent organic frameworks. J. Supercrit. Fluids 2018, 134, 197-203. [CrossRef]

75. Xu, F.; Wu, D.; Fu, R.; Wei, B. Design and preparation of porous carbons from conjugated polymer precursors. Mater. Today 2017, 20, 629-656. [CrossRef]

76. Yao, C.; Li, G.; Wang, J.; Xu, Y.; Chang, L. Template-free synthesis of porous carbon from triazine based polymers and their use in iodine adsorption and CO2 capture. Sci. Rep. 2018, 8, 1867. [CrossRef]

77. Feng, X.; Liang, Y.; Zhi, L.; Thomas, A.; Wu, D.; Lieberwirth, I.; Kolb, U.; Müllen, K. Synthesis of Microporous Carbon Nanofibers and Nanotubes from Conjugated Polymer Network and Evaluation in Electrochemical Capacitor. Adv. Funct. Mater. 2009, 19, 2125-2129. [CrossRef]

78. Xiang, Z.; Cao, D.; Huang, L.; Shui, J.; Wang, M.; Dai, L. Nitrogen-doped holey graphitic carbon from 2D covalent organic polymers for oxygen reduction. Adv. Mater. 2014, 26, 3315-3320. [CrossRef]

79. Paraknowitsch, J.P.; Thomas, A.; Schmidt, J. Microporous sulfur-doped carbon from thienyl-based polymer network precursors. Chem. Commun. 2011, 47, 8283. [CrossRef] [PubMed]

80. Bhosale, M.E.; Illathvalappil, R.; Kurungot, S.; Krishnamoorthy, K. Conjugated porous polymers as precursors for electrocatalysts and storage electrode materials. Chem. Commun. 2016, 52, 316-318. [CrossRef]

81. Wang, J.; Senkovska, I.; Oschatz, M.; Lohe, M.R.; Borchardt, L.; Heerwig, A.; Liu, Q.; Kaskel, S. Imine-linked polymer-derived nitrogen-doped microporous carbons with excellent $\mathrm{CO}_{2}$ capture properties. ACS Appl. Mater. Interfaces 2013, 5, 3160-3167. [CrossRef] [PubMed]

82. Shao, L.; Sang, Y.; Huang, J.; Liu, Y.-N. Triazine-based hyper-cross-linked polymers with inorganic-organic hybrid framework derived porous carbons for $\mathrm{CO}_{2}$ capture. Chem. Eng. J. 2018, 353, 1-14. [CrossRef]

83. Liu, X.; Zhou, L.; Zhao, Y.; Bian, L.; Feng, X.; Pu, Q. Hollow, Spherical Nitrogen-Rich Porous Carbon Shells Obtained from a Porous Organic Framework for the Supercapacitor. ACS Appl. Mater. Interfaces 2013, 5, 10280-10287. [CrossRef] [PubMed]

84. Kim, G.; Yang, J.; Nakashima, N.; Shiraki, T. Highly Microporous Nitrogen-doped Carbon Synthesized from Azine-linked Covalent Organic Framework and its Supercapacitor Function. Chem. A Eur. J. 2017, 23, 17504-17510. [CrossRef] [PubMed]

85. Zhu, X.; Tian, C.; Chai, S.; Nelson, K.; Han, K.S.; Hagaman, E.W.; Veith, G.M.; Mahurin, S.M.; Liu, H.; Dai, S. New tricks for old molecules: Development and application of porous N-doped, carbonaceous membranes for $\mathrm{CO}_{2}$ separation. Adv. Mater. 2013, 25, 4152-4158. [CrossRef]

86. Zhu, X.; Chai, S.; Tian, C.; Fulvio, P.F.; Han, K.S.; Hagaman, E.W.; Veith, G.M.; Mahurin, S.M.; Brown, S.; Liu, H.; et al. Synthesis of Porous, Nitrogen-Doped Adsorption/Diffusion Carbonaceous Membranes for Efficient $\mathrm{CO}_{2}$ Separation. Macromol. Rapid Commun. 2013, 34, 452-459. [CrossRef]

87. Zhu, Y.; Chen, X.; Liu, J.; Zhang, J.; Xu, D.Y.; Peng, W.; Li, Y.; Zhang, G.; Zhang, F.; Fan, X. Rational Design of Fe/N/S-Doped Nanoporous Carbon Catalysts from Covalent Triazine Frameworks for Efficient Oxygen Reduction. ChemSusChem 2018, 11, 2402-2409. [CrossRef]

88. Lee, Y.J.; Talapaneni, S.N.; Coskun, A. Chemically Activated Covalent Triazine Frameworks with Enhanced Textural Properties for High Capacity Gas Storage. ACS Appl. Mater. Interfaces 2017, 9, 30679-30685. [CrossRef] 
89. Kuhn, P.; Antonietti, M.; Thomas, A. Porous, covalent triazine-based frameworks prepared by ionothermal synthesis. Angew. Chem. Int. Ed. 2008, 47, 3450-3453. [CrossRef] [PubMed]

90. Puthiaraj, P.; Ahn, W.S. Facile synthesis of microporous carbonaceous materials derived from a covalent triazine polymer for $\mathrm{CO}_{2}$ capture. J. Energy Chem. 2017, 26, 965-971. [CrossRef]

91. Kim, M.; Puthiaraj, P.; Qian, Y.; Kim, Y.; Jang, S.; Hwang, S.; Na, E.; Ahn, W.-S.; Shim, S.E. High performance carbon supercapacitor electrodes derived from a triazine-based covalent organic polymer with regular porosity. Electrochim. Acta 2018, 284, 98-107. [CrossRef]

92. Jia, J.; Chen, Z.; Belmabkhout, Y.; Adil, K.; Bhatt, P.M.; Solovyeva, V.A.; Shekhah, O.; Eddaoudi, M. Carbonization of covalent triazine-based frameworks via ionic liquid induction. J. Mater. Chem. A 2018, 6, 15564-15568. [CrossRef]

93. Das, S.; Heasman, P.; Ben, T.; Qiu, S. Porous Organic Materials: Strategic Design and Structure-Function Correlation. Chem. Rev. 2017, 117, 1515-1563. [CrossRef] [PubMed]

94. Huang, Y.-B.; Pachfule, P.; Sun, J.-K.; Xu, Q. From covalent-organic frameworks to hierarchically porous B-doped carbons: A molten-salt approach. J. Mater. Chem. A 2016, 4, 4273-4279. [CrossRef]

95. Bai, C.; Li, J.; Liu, S.; Yang, X.; Yang, X.; Tian, Y.; Cao, K.; Huang, Y.; Ma, L.; Li, S. In situ preparation of nitrogen-rich and functional ultramicroporous carbonaceous COFs by "segregated" microwave irradiation. Microporous Mesoporous Mater. 2014, 197, 148-155. [CrossRef]

96. Wang, L.; Hu, X. Recent Advances in Porous Carbon Materials for Electrochemical Energy Storage. Chem. Asian J. 2018, 13, 1518-1529. [CrossRef]

97. Xu, Q.; Tang, Y.; Zhang, X.; Oshima, Y.; Chen, Q.; Jiang, D. Template Conversion of Covalent Organic Frameworks into 2D Conducting Nanocarbons for Catalyzing Oxygen Reduction Reaction. Adv. Mater. 2018, 30, 1706330. [CrossRef]

98. Kim, D.J.; Yoon, J.W.; Lee, C.S.; Bae, Y.S.; Kim, J.H. Covalent organic framework-derived microporous carbon nanoparticles coated with conducting polypyrrole as an electrochemical capacitor. Appl. Surf. Sci. 2018, 439, 833-838. [CrossRef]

99. Zhang, X.; Wang, Z.; Yao, L.; Mai, Y.; Liu, J.; Hua, X.; Wei, H. Synthesis of core-shell covalent organic frameworks/multi-walled carbon nanotubes nanocomposite and application in lithium-sulfur batteries. Mater. Lett. 2018, 213, 143-147. [CrossRef]

100. Chen, L.; Zhang, L.; Chen, Z.; Liu, H.; Luque, R.; Li, Y. A covalent organic framework-based route to the: In situ encapsulation of metal nanoparticles in N-rich hollow carbon spheres. Chem. Sci. 2016, 7, 6015-6020. [CrossRef] [PubMed]

101. Liu, B.; Shioyama, H.; Akita, T.; Xu, Q. Metal-organic framework as a template for porous carbon synthesis. J. Am. Chem. Soc. 2008, 130, 5390-5391. [CrossRef] [PubMed]

102. Dang, S.; Zhu, Q.L.; Xu, Q. Nanomaterials derived from metal-organic frameworks. Nat. Rev. Mater. 2017, 3, 17075. [CrossRef]

103. Zhang, L.; Hu, Y.H. A systematic investigation of decomposition of nano $\mathrm{Zn}_{4} \mathrm{O}\left(\mathrm{C}_{8} \mathrm{H}_{4} \mathrm{O}_{4}\right)_{3}$ metal-organic framework. J. Phys. Chem. C 2010, 114, 2566-2572. [CrossRef]

104. Hu, J.; Wang, H.; Gao, Q.; Guo, H. Porous carbons prepared by using metal-organic framework as the precursor for supercapacitors. Carbon N. Y. 2010, 48, 3599-3606. [CrossRef]

105. Jin, S.L.; Deng, H.G.; Zhan, L.; Qiao, W.M.; Ling, L.C. Synthesis of 3D hierarchical porous carbon as an electrode material for electric double layer capacitors. Xinxing Tan Cailiao/New Carbon Mater. 2012, 27, 87-92. [CrossRef]

106. Mo, S.; Sun, Z.; Huang, X.; Zou, W.; Chen, J.; Yuan, D. Synthesis, characterization and supercapacitive properties of hierarchical porous carbons. Synth. Met. 2012, 162, 85-88. [CrossRef]

107. Yuan, D.; Chen, J.; Tan, S.; Xia, N.; Liu, Y. Worm-like mesoporous carbon synthesized from metal-organic coordination polymers for supercapacitors. Electrochem. Commun. 2009, 11, 1191-1194. [CrossRef]

108. Srinivas, G.; Krungleviciute, V.; Guo, Z.X.; Yildirim, T. Exceptional $\mathrm{CO}_{2}$ capture in a hierarchically porous carbon with simultaneous high surface area and pore volume. Energy Environ. Sci. 2014, 7, 335-342. [CrossRef]

109. Yang, S.J.; Kim, T.; Im, J.H.; Kim, Y.S.; Lee, K.; Jung, H.; Park, C.R. MOF-derived hierarchically porous carbon with exceptional porosity and hydrogen storage capacity. Chem. Mater. 2012, 24, 464-470. [CrossRef] 
110. Wang, M.; Xu, X.; Liu, Y.; Li, Y.; Lu, T.; Pan, L. From metal-organic frameworks to porous carbons: A promising strategy to prepare high-performance electrode materials for capacitive deionization. Carbon $N$. Y. 2016, 108, 433-439. [CrossRef]

111. Ding, M.; Shi, W.; Guo, L.; Leong, Z.Y.; Baji, A.; Yang, H.Y. Bimetallic metal-organic framework derived porous carbon nanostructures for high performance membrane capacitive desalination. J. Mater. Chem. A 2017, 5, 6113-6121. [CrossRef]

112. Roberts, A.D.; Li, X.; Zhang, H. Porous carbon spheres and monoliths: Morphology control, pore size tuning and their applications as Li-ion battery anode materials. Chem. Soc. Rev. 2014, 43, 4341-4356. [CrossRef] [PubMed]

113. Li, Z.; Xu, Z.; Tan, X.; Wang, H.; Holt, C.M.B.; Stephenson, T.; Olsen, B.C.; Mitlin, D. Mesoporous nitrogen-rich carbons derived from protein for ultra-high capacity battery anodes and supercapacitors. Energy Environ. Sci. 2013, 6, 871. [CrossRef]

114. Li, A.; Song, H.; Bian, Z.; Shi, L.; Chen, X.; Zhou, J. ZnO nanosheet/squeezebox-like porous carbon composites synthesized by in situ pyrolysis of a mixed-ligand metal-organic framework. J. Mater. Chem. A 2017, 5, 5934-5942. [CrossRef]

115. Indra, A.; Song, T.; Paik, U. Metal Organic Framework Derived Materials: Progress and Prospects for the Energy Conversion and Storage. Adv. Mater. 2018, 30, 1705146. [CrossRef]

116. Zhu, D.; Li, H.; Su, Y.; Jiang, M. Pyridine-containing metal-organic frameworks as precursor for nitrogen-doped porous carbons with high-performance capacitive behavior. J. Solid State Electrochem. 2017, 21, 2037-2045. [CrossRef]

117. Xu, J.; Xia, J.; Zhang, F.; Wang, Z. An electrochemical sensor based on metal-organic framework-derived porous carbon with high degree of graphitization for electroanalysis of various substances. Electrochim. Acta 2017, 251, 71-80. [CrossRef]

118. Pan, Y.; Zhao, Y.; Mu, S.; Wang, Y.; Jiang, C.; Liu, Q.; Fang, Q.; Xue, M.; Qiu, S. Cation exchanged MOF-derived nitrogen-doped porous carbons for $\mathrm{CO}_{2}$ capture and supercapacitor electrode materials. J. Mater. Chem. A 2017, 5, 9544-9552. [CrossRef]

119. Wang, H.; Zhang, X.; Wang, Y.; Quan, G.; Han, X.; Yan, J. Facile Synthesis of Magnetic Nitrogen-Doped Porous Carbon from Bimetallic Metal-Organic Frameworks for Efficient Norfloxacin Removal. Nanomaterials 2018, 8, 664. [CrossRef] [PubMed]

120. Nadeem, M.; Yasin, G.; Bhatti, M.H.; Mehmood, M.; Arif, M.; Dai, L. Pt-M bimetallic nanoparticles (M = $\mathrm{Ni}, \mathrm{Cu}, \mathrm{Er}$ ) supported on metal organic framework-derived $\mathrm{N}$-doped nanostructured carbon for hydrogen evolution and oxygen evolution reaction. J. Power Sources 2018, 402, 34-42. [CrossRef]

121. Dhawa, T.; Chattopadhyay, S.; De, G.; Mahanty, S. In Situ Mg/MgO-Embedded Mesoporous Carbon Derived from Magnesium 1,4-Benzenedicarboxylate Metal Organic Framework as Sustainable Li-S Battery Cathode Support. ACS Omega 2017, 2, 6481-6491. [CrossRef]

122. Ulrich, H. Raw Materials for Industrial Polymers; Hanser Publishers: Munich, Germany, 1988; ISBN 3446150994.

123. Wang, X.; Li, Y. Nanoporous carbons derived from MOFs as metal-free catalysts for selective aerobic oxidations. J. Mater. Chem. A 2016, 4, 5247-5257. [CrossRef]

124. Zhou, Y.; Long, J.; Li, Y. Ni-based catalysts derived from a metal-organic framework for selective oxidation of alkanes. Cuihua Xuebao/Chin. J. Catal. 2016, 37, 955-962. [CrossRef]

125. Tojo, G.; Fernandez, M.I. Oxidation of Alcohols to Aldehydes and Ketones; Basic Reactions in Organic Synthesis; Springer: New York, NY, USA, 2006; ISBN 0-387-23607-4.

126. Bai, C.; Li, A.; Yao, X.; Liu, H.; Li, Y. Efficient and selective aerobic oxidation of alcohols catalysed by MOF-derived Co catalysts. In Green Chemistry; The Royal Society of Chemistry: London, UK, 2016; Volume 18, pp. 1061-1069.

127. Kim, B.R.; Oh, J.S.; Kim, J.; Lee, C.Y. Robust Aerobic Alcohol Oxidation Catalyst Derived from Metal-Organic Frameworks. Catal. Lett. 2016, 146, 734-743. [CrossRef]

128. Otera, J. Esterification: Methods, Reactions and Applications; Wiley-VCH: Weinheim, Germany, 2003; ISBN 3527304908.

129. Zhou, Y.-X.; Chen, Y.-Z.; Cao, L.; Lu, J.; Jiang, H.-L. Conversion of a metal-organic framework to N-doped porous carbon incorporating $\mathrm{Co}$ and $\mathrm{CoO}$ nanoparticles: Direct oxidation of alcohols to esters. Chem. Commun. 2015, 51, 8292-8295. [CrossRef] [PubMed] 
130. Zhong, W.; Liu, H.; Bai, C.; Liao, S.; Li, Y. Base-free oxidation of alcohols to esters at room temperature and atmospheric conditions using nanoscale Co-based catalysts. ACS Catal. 2015, 5, 1850-1856. [CrossRef]

131. Fang, R.; Luque, R.; Li, Y. Selective aerobic oxidation of biomass-derived HMF to 2,5-diformylfuran using a MOF-derived magnetic hollow Fe-Co nanocatalyst. Green Chem. 2016, 18, 3152-3157. [CrossRef]

132. Liao, Y.T.; Matsagar, B.M.; Wu, K.C.-W. Metal-Organic Framework (MOF)-Derived Effective Solid Catalysts for Valorization of Lignocellulosic Biomass. ACS Sustain. Chem. Eng. 2018, 6, 13628-13643. [CrossRef]

133. Bai, C.; Yao, X.; Li, Y. Easy access to amides through aldehydic C-H bond functionalization catalyzed by heterogeneous Co-based catalysts. ACS Catal. 2015, 5, 884-891. [CrossRef]

134. Long, J.; Zhou, Y.; Li, Y. Transfer hydrogenation of unsaturated bonds in the absence of base additives catalyzed by a cobalt-based heterogeneous catalyst. Chem. Commun. 2015, 51, 2331-2334. [CrossRef] [PubMed]

135. Liu, X.; Cheng, S.; Long, J.; Zhang, W.; Liu, X.; Wei, D. MOFs-Derived Co@CN bi-functional catalysts for selective transfer hydrogenation of $\alpha, \beta$-unsaturated aldehydes without use of base additives. Mater. Chem. Front. 2017, 1, 2005-2012. [CrossRef]

136. Li, Y.; Zhou, Y.X.; Ma, X.; Jiang, H.L. A metal-organic framework-templated synthesis of $\gamma-\mathrm{Fe}_{2} \mathrm{O}_{3}$ nanoparticles encapsulated in porous carbon for efficient and chemoselective hydrogenation of nitro compounds. Chem. Commun. 2016, 52, 4199-4202. [CrossRef] [PubMed]

137. Niu, H.; Liu, S.; Cai, Y.; Wu, F.; Zhao, X. MOF derived porous carbon supported $\mathrm{Cu} / \mathrm{Cu}_{2} \mathrm{O}$ composite as high performance non-noble catalyst. Microporous Mesoporous Mater. 2016, 219, 48-53. [CrossRef]

138. Tang, B.; Song, W.C.; Yang, E.C.; Zhao, X.J. MOF-derived Ni-based nanocomposites as robust catalysts for chemoselective hydrogenation of functionalized nitro compounds. RSC Adv. 2017, 7, 1531-1539. [CrossRef]

139. Shen, K.; Chen, L.; Long, J.; Zhong, W.; Li, Y. MOFs-Templated Co@Pd Core-Shell NPs Embedded in N-Doped Carbon Matrix with Superior Hydrogenation Activities. ACS Catal. 2015, 5, 5264-5271. [CrossRef]

140. Yang, H.; Bradley, S.J.; Chan, A.; Waterhouse, G.I.N.; Nann, T.; Kruger, P.E.; Telfer, S.G. Catalytically Active Bimetallic Nanoparticles Supported on Porous Carbon Capsules Derived from Metal-Organic Framework Composites. J. Am. Chem. Soc. 2016, 138, 11872-11881. [CrossRef]

141. Long, J.; Shen, K.; Li, Y. Bifunctional N-Doped Co@C Catalysts for Base-Free Transfer Hydrogenations of Nitriles: Controllable Selectivity to Primary Amines vs. Imines. ACS Catal. 2017, 7, 275-284. [CrossRef]

142. Long, J.; Shen, K.; Chen, L.; Li, Y. Multimetal-MOF-derived transition metal alloy NPs embedded in an $\mathrm{N}$-doped carbon matrix: Highly active catalysts for hydrogenation reactions. J. Mater. Chem. A 2016, 4, 10254-10262. [CrossRef]

143. Wang, X.; Chen, W.; Zhang, L.; Yao, T.; Liu, W.; Lin, Y.; Ju, H.; Dong, J.; Zheng, L.; Yan, W.; et al. Uncoordinated Amine Groups of Metal-Organic Frameworks to Anchor Single Ru Sites as Chemoselective Catalysts toward the Hydrogenation of Quinoline. J. Am. Chem. Soc. 2017, 139, 9419-9422. [CrossRef] [PubMed]

144. Ding, S.; Zhang, C.; Liu, Y.; Jiang, H.; Xing, W.; Chen, R. Pd nanoparticles supported on N-doped porous carbons derived from ZIF-67: Enhanced catalytic performance in phenol hydrogenation. J. Ind. Eng. Chem. 2017, 46, 258-265. [CrossRef]

145. Wang, Y.; Sang, S.; Zhu, W.; Gao, L.; Xiao, G. CuNi@C catalysts with high activity derived from metal-organic frameworks precursor for conversion of furfural to cyclopentanone. Chem. Eng. J. 2016, 299, 104-111. [CrossRef]

146. Ricci, A. Amino Group Chemistry: From Synthesis to the Life Sciences; Ricci, A., Ed.; Wiley-VCH Verlag GmbH \& Co. KGaA: Weinheim, Germany, 2008; ISBN 9783527317417.

147. Dewick, P.M. Medicinal Natural Product: A Biosynthetic Approach; Wiley: New York, NY, USA, 2002; Volume 0471496405, ISBN 978-0-470-74168-9.

148. Jagadeesh, R.V.; Murugesan, K.; Alshammari, A.S.; Neumann, H.; Pohl, M.M.; Radnik, J.; Beller, M. MOF-derived cobalt nanoparticles catalyze a general synthesis of amines. Science 2017, 358, 326-332. [CrossRef] [PubMed]

149. Pérez-Mayoral, E.; Calvino-Casilda, V.; Godino, M.; López-Peinado, A.J.; Martín-Aranda, R.M. Green Synthetic Approaches for Biologically Relevant Heterocycles: An Overview. In Green Synthetic Approaches for Biologically Relevant Heterocycles; Brahmachari, G., Ed.; Elsevier: New York, NY, USA, 2015; pp. 378-403. ISBN 9780128005903. 
150. Li, X.; Zhang, B.; Fang, Y.; Sun, W.; Qi, Z.; Pei, Y.; Qi, S.; Yuan, P.; Luan, X.; Goh, T.W.; et al. Metal-Organic-Framework-Derived Carbons: Applications as Solid-Base Catalyst and Support for Pd Nanoparticles in Tandem Catalysis. Chem. Eur. J. 2017, 23, 4266-4270. [CrossRef] [PubMed]

151. Yoon, Y.; Kim, B.R.; Lee, C.Y.; Kim, J. Heterogeneous Copper-Catalyzed Aerobic Oxidative Conversions of Benzaldehydes with Aqueous Ammonia to Give Benzonitriles. Asian J. Org. Chem. 2016, 5, 746-749. [CrossRef]

152. Pérez-Mayoral, E.; Calvino-Casilda, V.; Soriano, E. Metal-supported carbon-based materials: Opportunities and challenges in the synthesis of valuable products. Catal. Sci. Technol. 2016, 6, 1265-1291. [CrossRef]

153. Li, X.; Zhang, J.; Li, W. MOF-derived nitrogen-doped porous carbon as metal-free catalysts for acetylene hydrochlorination. J. Ind. Eng. Chem. 2016, 44, 146-154. [CrossRef]

154. Chao, S.; Zou, F.; Wan, F.; Dong, X.; Wang, Y.; Wang, Y.; Guan, Q.; Wang, G.; Li, W. Nitrogen-doped Carbon Derived from ZIF-8 as a High-performance Metal-free Catalyst for Acetylene Hydrochlorination. Sci. Rep. 2017, 7, 39789. [CrossRef]

155. Kim, M.J.; Kim, B.R.; Lee, C.Y.; Kim, J. N-Sulfonyl amidine synthesis via three-component coupling reaction using heterogeneous copper catalyst derived from metal-organic frameworks. Tetrahedron Lett. 2016, 57, 4070-4073. [CrossRef]

156. Li, L.; Li, L.; Cui, C.; Fan, H.; Wang, R. Heteroatom-doped Carbon Spheres from Hierarchical Hollow Covalent Organic Framework Precursors for Metal-Free Catalysis. ChemSusChem 2017, 10, 4921-4926. [CrossRef] [PubMed]

157. Hu, X.; Long, Y.; Fan, M.; Yuan, M.; Zhao, H.; Ma, J.; Dong, Z. Two-dimensional covalent organic frameworks as self-template derived nitrogen-doped carbon nanosheets for eco-friendly metal-free catalysis. Appl. Catal. B Environ. 2019, 244, 25-35. [CrossRef]

158. Friščić, T.; Julien, P.A.; Mottillo, C. Environmentally-Friendly Designs and Syntheses of Metal-Organic Frameworks (MOFs). In Green Technologies for the Environment; American Chemical Society: Washington, DC, USA, 2014; pp. 161-183. ISBN 9780841230187.

159. Julien, P.A.; Mottillo, C.; Friščić, T. Metal-organic frameworks meet scalable and sustainable synthesis. Green Chem. 2017, 19, 2729-2747. [CrossRef]

160. Godino-Ojer, M.; López-Peinado, A.J.; Maldonado-Hódar, F.J.; Pérez-Mayoral, E. Highly Efficient and Selective Catalytic Synthesis of Quinolines Involving Transition-Metal-Doped Carbon Aerogels. ChemCatChem 2017, 9, 1422-1428. [CrossRef]

161. Pérez-Mayoral, E.; Soriano, E.; Martín-Aranda, R.M. Maldonado-Hódar, F.J. Mesoporous Catalytic Materials and Fine Chemistry. In Comprehensive Guide for Mesoporous Materials. Volume 1: Synthesis and Characterization; Aliofkhazrae, M., Ed.; Nova Science Publishers, Inc.: Hauppauge, NY, USA, 2015; pp. 83-118. ISBN 978-1-63463-990-3.

162. Yang, X.-F.; Wang, A.; Qiao, B.; Li, J.; Liu, J.; Zhang, T. Single-Atom Catalysts: A New Frontier in Heterogeneous Catalysis. Acc. Chem. Res. 2013, 46, 1740-1748. [CrossRef] [PubMed]

163. Herzing, A.A.; Kiely, C.J.; Carley, A.F.; Landon, P.; Hutchings, G.J. Identification of active gold nanoclusters on iron oxide supports for CO oxidation. Science 2008, 321, 1331-1335. [CrossRef] [PubMed]

164. Gong, Y.T.; Li, B.H.; Pei, T.; Lin, C.H.; Lee, S. Raman investigation on carbonization process of metal-organic frameworks. J. Raman Spectrosc. 2016, 47, 1271-1275. [CrossRef]

(C) 2019 by the authors. Licensee MDPI, Basel, Switzerland. This article is an open access article distributed under the terms and conditions of the Creative Commons Attribution (CC BY) license (http://creativecommons.org/licenses/by/4.0/). 